Research Article

\title{
Study on Seismic Performance of Porcelain Pillar Electrical Equipment Based on Nonlinear Dynamic Theory
}

\author{
Yaodong Xue $\mathbb{D}^{1}{ }^{1}$ Yongfeng Cheng, ${ }^{1}$ Zhubing Zhu, ${ }^{1}$ Sheng Li, ${ }^{1}$ Zhenlin Liu, \\ Hulun Guo, ${ }^{2}$ and Shujun Zhang $^{3}$ \\ ${ }^{1}$ China Electric Power Research Institute, Beijing 100055, China \\ ${ }^{2}$ Tianjin University, Tianjin 300072, China \\ ${ }^{3}$ State Grid Zhejiang Electric Power Co., Ltd., Hangzhou 310007, China
}

Correspondence should be addressed to Yaodong Xue; xuecumtb@163.com

Received 28 August 2020; Revised 9 January 2021; Accepted 27 January 2021; Published 8 February 2021

Academic Editor: Fabrizio Paolacci

Copyright (C) 2021 Yaodong Xue et al. This is an open access article distributed under the Creative Commons Attribution License, which permits unrestricted use, distribution, and reproduction in any medium, provided the original work is properly cited.

In order to consider the influence of nonlinear characteristics of porcelain pillar electrical equipment on the dynamic response under seismic excitation, a theoretical analysis method of nonlinear dynamics was raised to define the nonlinear parameter of the flange connection and establish a dynamic model of porcelain pillar electrical equipment. The theoretical analysis and the test results have a good degree of fitting, which verifies the correctness of the dynamic model and reveals the nonlinear seismic response law of the porcelain pillar equipment. According to the results, both the nonlinear calculation results of the displacement at the top end of the porcelain pillar and the stress at the bottom end of the porcelain pillar are smaller than the results in the linear calculation. The difference between them increases gradually with the increase of seismic excitation. The differences in displacement and stress at a seismic excitation of $0.5 \mathrm{~g}$ are $14.58 \%$ and $23.25 \%$, respectively. When the nonlinear parameter increases to a certain value, the impact of maximum stress on the bottom of the porcelain pillar is very small and the change is not obvious. The research provides a theoretical reference for the seismic design of pillar electrical equipment.

\section{Introduction}

The electric power system is an important part of the lifeline project, which is related to the normal life of the people and the development of industry and manufacturing. The earthquakes have caused serious damage to the electrical equipment. An electrical substation, as the node of an electrical grid, is extremely important for the reliable service of an electrical grid system [1]. A wide variety of porcelain pillar electrical equipment, such as post insulators and surge arresters, is a major component of an electrical substation [2]. Due to the brittle nature of porcelain, equipment made of porcelain is vulnerable to earthquake shaking. For porcelain pillar electrical equipment when it is subjected to earthquake, due to the small rigidity of the cemented part of the flange connection, it is prone to damage at the flange connection. The post-earthquake field investigation and shaking table tests (Figures 1 and 2) showed failure characteristics of fracture during the earthquake damage [3-5].

Many scholars have conducted extensive researches on the seismic response mechanism of porcelain pillars. Chinese codes are given in [6-9] combined with experimental research. In the recommended practice in the relevant code, the calculation equation for the bending stiffness of the joint between the flange and the porcelain bushing is

$$
K_{c}=\left(\beta \cdot d_{c} \cdot \frac{h_{c}^{2}}{t_{e}}\right) \times 10^{7}
$$

in which $K_{c}$ is the bending stiffness of the connection between the flange and the porcelain bushing (in N.m/rad); $d_{c}$ is the porcelain bushing outer diameter (in $\mathrm{m}$ ); $h_{c}$ is the height of porcelain bushing at cemented part (in $\mathrm{m}$ ); $t_{e}$ is the thickness of the cemented part between the flange and the 


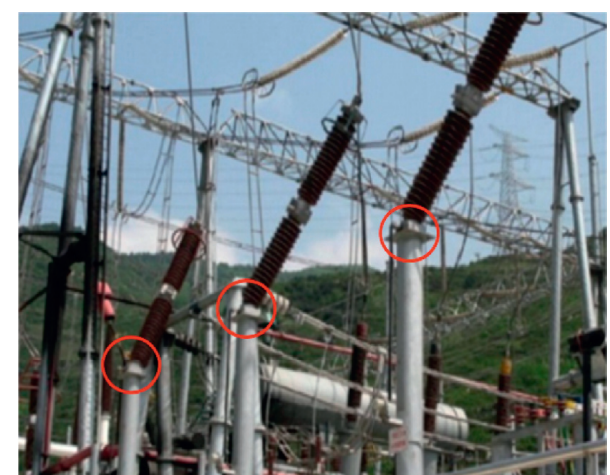

FIgURE 1: Failure of porcelain equipment after 2008 Wenchuan Earthquake [3].

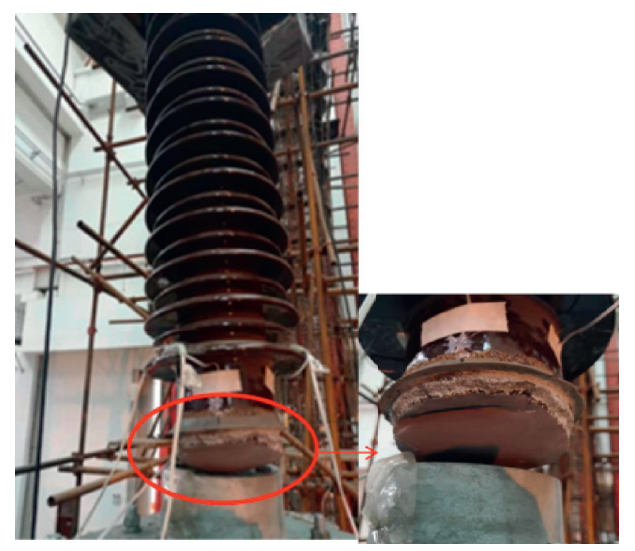

FIgURE 2: Failure of $110 \mathrm{kV}$ post insulator after shaking table test.

porcelain bushing (in $\mathrm{m}$ ) (refer to Figure 3(a)); and $\beta$ is the calculation parameter of the bending stiffness of the joint between the porcelain bushing and the flange, which is recommended as $\beta=6.54 \times 10^{7}$ in the Chinese code. The physical concept of the above equation is relatively clear, which basically reflects the mechanical characteristics of the cement layer between the flange and the porcelain bushing. For the bolted connection, the bolts are usually pretensioned and there is no opening between the two faces when the equipment is subjected to bending moment. The stiffness of bolted connection can be assumed infinitely large. Therefore, the stiffness between metal cap and porcelain pillar is weaker and the bending capacity is determined by stiffness between metal cap and porcelain pillar. However, its accuracy depends on the empirical parameter of the bending stiffness of the porcelain bushing and the flange.

Zhang et al. [10] obtained the bending rigidity calculation parameter for the connections between UHV porcelain bushing and flange by conducting the bending rigidity test and, accordingly, applied this calculation parameter to the finite element calculation of the simulated UHV porcelain bushings. Singh et al. [11] introduced the response spectrum analysis to evaluate linear control systems for seismic inputs defined by code-prescribed or site-specific ground response spectra. Gilani et al. [12] carried out a shaking table test for two $230 \mathrm{kV}, 3000 \mathrm{~A}$, Type-U transformer bushings and found that both bushings survived earthquake shaking compatible with the IEEE spectrum for high-level qualification when mounted on a rigid frame. When mounted on a flexible frame, one $230 \mathrm{kV}$ bushing was unable to sustain the high-level qualification shaking without oil leakage and a slip of the porcelain units. Filiatrault and Matt [13] investigated numerically the dynamic response of porcelain bushings mounted on transformer tanks. The results of the numerical study show that large amplification occurs when the fundamental frequency of the porcelain bushing is tuned with the fundamental frequency of the transformer tank. Bender and Farid [14] added additional evidence that bushing amplifications greater than 2.0 are possible, and they demonstrated that the complexity of these systems makes generalizations of design. Villaverde et al. [15] undertook the study to assess the adequacy of the amplification factor of 2.0 specified by the Institute of Electrical and Electronics Engineers in Standard IEEE 6931997 for the seismic qualification of transformer bushings. Schiff [16] proposed a new method to seismically qualify power transformers and their bushings to meet the requirements of IEEE Standard 693. He et al. [17] analyzed the influence of different types of connections on the seismic responses of the oil-side bushings and a simplified method to rapidly estimate the seismic responses of transformer bushings was implemented.

Cao [18] conducted the characteristic research on the recovery capacity of pillar insulators and discussed the impact of various factors such as the insulator cementing parts between insulator flange and porcelain body on the seismic performance of insulator pillars. Schiff [19] presented a method for evaluating the reliability of ceramic structural members subjected to earthquake-induced vibrations which used the Weibull distribution to represent the probability of failure of the brittle ceramic material. The authors of [20-22] introduce the experimental study of seismic performance of pillar electrical equipment of different voltage classes and different types. In order to improve the seismic capacity of pillar electrical equipment, composite materials are often used in the porcelain pillar equipment. IEC 61462 [23] and IEEE Std 693-2005 [24] introduce the research on the improvement of bearing capacity of porcelain pillar equipment by using new composite materials. Mohammadi et al. [25] proposed a Four Degrees-of-Freedom (4-DOF) system in order to assess the dynamic properties of substation support structures and verified through the finite element method (FEM).

In the above researches, during the seismic analysis of porcelain pillar electrical equipment, the beams with equivalent rigidity are often used directly to represent the flange connections. This paper focuses on the nonlinear factors at the flange connections by introducing a nonlinear rigidity parameter. The nonlinear dynamic model is then established. After that, the seismic performance of multiple porcelain pillars is studied and compared with the shaking table test results, which proved the correctness of the nonlinear dynamic model. Finally, the maximum stresses at the bottom of porcelain pillars are analyzed when the 


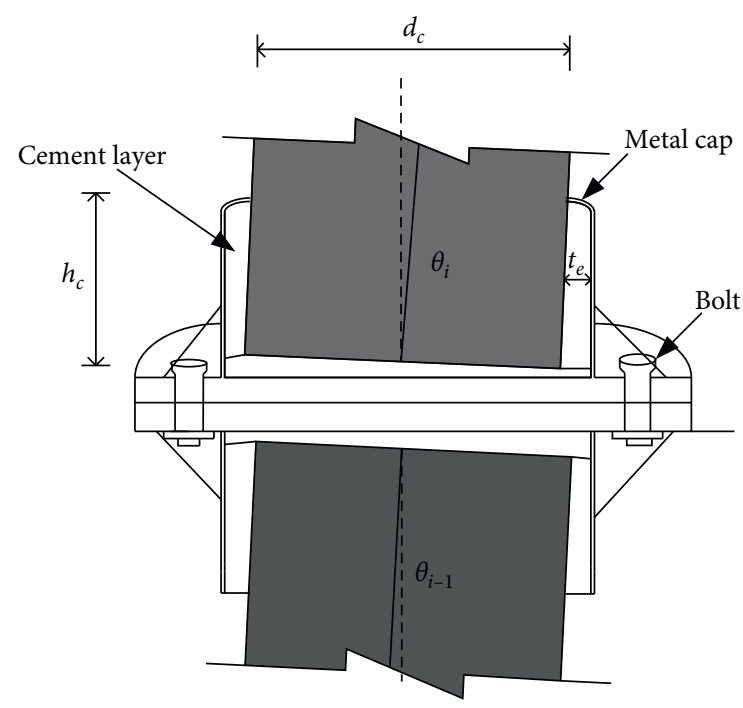

(a)

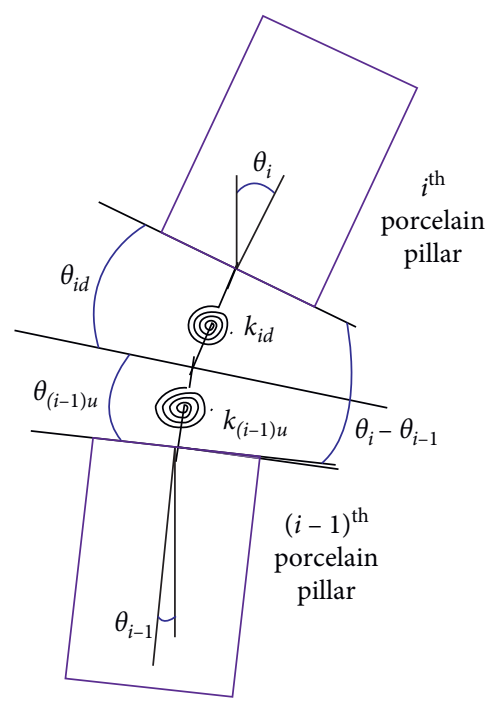

(b)

FIGURE 3: Analysis diagram of flange connections. (a) Deformation diagram of the cemented joint. (b) Mechanical model of flange connection.

nonlinear rigidity parameter changes. The maximum stress at the bottom of the porcelain pillar with a different seismic excitation can be predicted through this way.

\section{Nonlinear Dynamic Model of Porcelain Pillar Equipment}

In an electrical substation, some porcelain pillar equipment is directly installed on the foundations. Take a piece of typical flanged 4-section porcelain post insulator as an example, as illustrated in Figure 4. Figure 4 also shows the key structural and typical sections of a solid core post insulator with sheds. The equipment has structural characteristics (1): the main body of the equipment is made of porcelain core as annotated in Figure 4; (2) the porcelain component is connected through metal caps at both ends with bolted flange connections. The connections between porcelain pillars contain two parts, cemented connections between metal caps and flange, and connection between two flanges with bolts.

Figure 5 is an analysis diagram of the porcelain pillar equipment structure, where $x_{b}$ is the seismic excitation, and the sequential numbers of porcelain pillars are 1,2,3, and 4 , respectively, from bottom to top. The equipment is mainly in a bending state when it is subjected to seismic and the flange connection between two pieces of porcelain pillars rotates by a certain angle $\theta$. The bottom end of the upper porcelain pillar rotates by $\theta_{i}$, and the upper end of the lower porcelain rotates by $\theta_{i-1}$. So, the relative angle $\theta$ can be expressed as $\theta=\theta_{i}-\theta_{i-1}$. The angles of each flange connection are $\theta_{1}, \theta_{2}$, $\theta_{3}$, and $\theta_{4}$, respectively, as shown in Figure 5 .

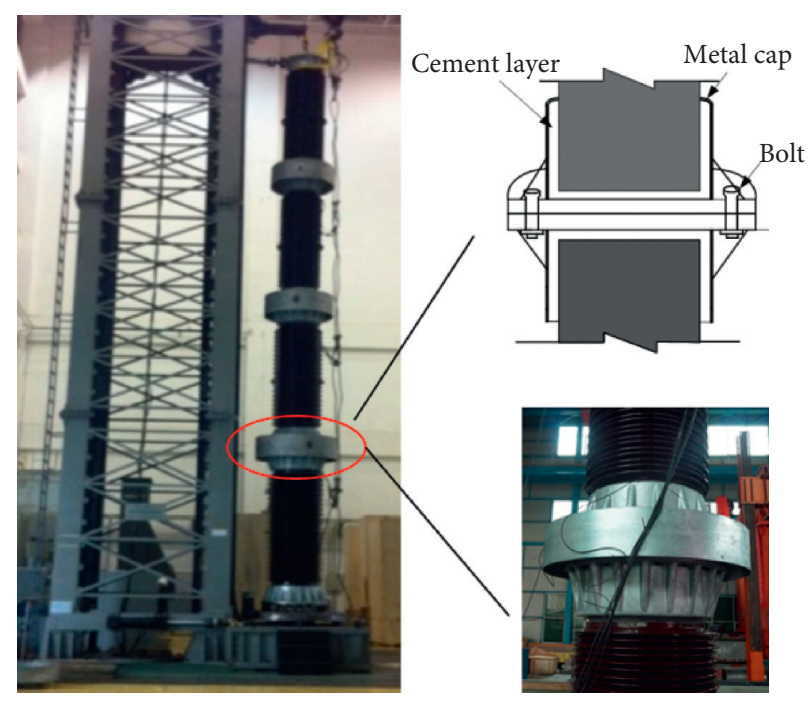

Figure 4: Porcelain pillar equipment.

The analysis diagram of flange connections is illustrated in Figure 3. Figure 3(a) shows the deformation of the cemented part. Figure 3(b) shows the mechanical simplified diagram of the flange connection. According to the deformation characteristics, the connection between porcelain and metal cap can be regarded as a spring with rigidity $k_{i d}$. Correspondingly, the connection between lower porcelain and flange can be regarded as a spring with rigidity $k_{(i-1) u}$. The cemented part between metal caps and flange can be equivalent to a series spring with the equivalent rigidity $k_{i}$, and $k_{i}$, can be expressed as follows: 


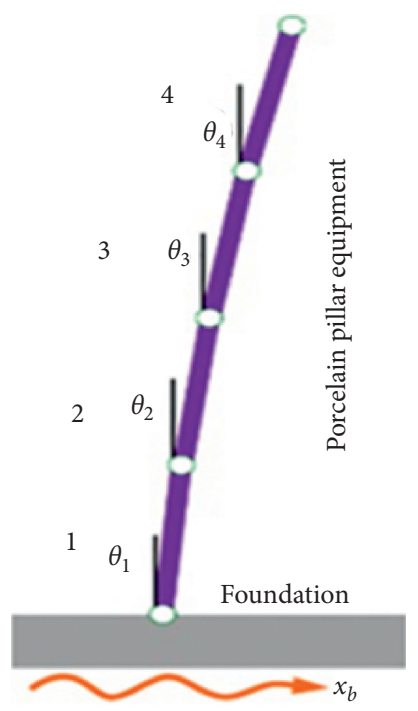

FIGURE 5: Analysis diagram of porcelain pillar equipment.

$$
k_{i}=\frac{k_{i d} k_{(i-1) u}}{k_{i d}+k_{(i-1) u}}
$$

where $k_{i d}$ and $k_{(i-1) u}$ are calculated as follows [2]:

$$
\begin{aligned}
k_{i d} & =\beta_{d} \frac{d_{d} h_{d}^{2}}{t_{d}}, \\
k_{(i-1) u} & =\beta_{u} \frac{d_{u} h_{u}^{2}}{t_{u}},
\end{aligned}
$$

in which $d_{u}$ and $d_{d}$ are the porcelain diameters at cemented parts of $(i-1)^{\text {th }}$ and $i^{\text {th }}$ porcelain pillar, respectively; $h_{u}$ and $h_{d}$ are the cemented heights of $(i-1)^{\text {th }}$ and $i^{\text {th }}$ porcelain pillar, respectively; $t_{u}$ and $t_{d}$ are the thicknesses of cement layer of $(i-1)^{\text {th }}$ and $i^{\text {th }}$ porcelain pillar, respectively; $\beta_{u}$ and $\beta_{d}$ are bending rigidity parameters at the connections of $(i-1)^{\text {th }}$ and $i^{\text {th }}$ porcelain pillar, respectively, the value of $\beta$ is $6.54 \times 10^{7}$ when the porcelain diameter at the cemented part is smaller than $275 \mathrm{~mm}$, the value of $\beta$ is $5.0 \times 10^{7}$ when the porcelain diameter at the cemented part is larger than $375 \mathrm{~mm}$, and the value of $\beta$ can be obtained by linear interpolation when the porcelain diameter at the cemented part is between $275 \mathrm{~mm}$ to $375 \mathrm{~mm}$.

As can be seen from the above analysis, the rotational bending moment caused by the relative rotation of the up and down flanges can be expressed using

$$
M_{i}=k_{i}\left(\theta_{i}-\theta_{i-1}\right) \text {. }
$$

Equation (4) expresses rotational bending moment under ideal conditions. The exact mechanics of the rotation stiffness $k_{i}$ is complex, which involves nonlinear mechanical properties of the cemented material and the mechanics at the contact interfaces. These factors should be included in $M_{i}$ to make it more realistic. In most previous studies, the flange joint was equivalent to a beam with equivalent rotational stiffness $[2,26,27]$. Figure 6 shows a diagram of the force of

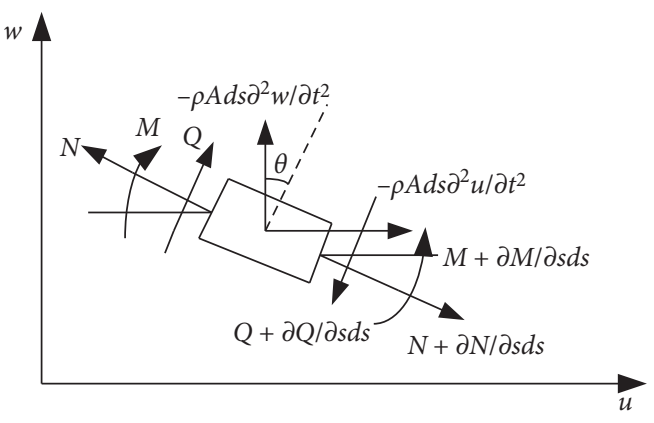

Figure 6: Force diagram of the microelement.

the microelement. According to the elastic theory, when the beam subjected to large deformation, the strain can be expressed as

$$
\varepsilon=\left[\frac{\partial u}{\partial x}+z \frac{\partial \theta}{\partial x}+\frac{1}{2}\left(\frac{\partial w}{\partial x}\right)^{2}\right] \cos \theta
$$

in which $u$ represents the horizontal displacement, $\theta$ represents the rotational angle, and wrepresents the curvature.

Then, the stress can be calculated using

$$
\sigma=E \varepsilon
$$

in which $E$ represents Young's modulus.

Further, the bending moment on the cross section of the porcelain bushing is

$M(x, t)=\iint_{A} z \sigma \mathrm{d} A=\iint_{A} E z E z\left[\frac{\partial u}{\partial x}+z \frac{\partial \theta}{\partial x}+\frac{1}{2}\left(\frac{\partial w}{\partial x}\right)^{2}\right]$

$\cos \theta \mathrm{d} A$

in which $A$ represents the area of cross section.

In addition,

$$
\begin{gathered}
\iint_{A} z \mathrm{~d} A=0, \\
\iint_{A} z^{2} \mathrm{~d} A=I,
\end{gathered}
$$

In equation (8), I represents the moment of inertia.

Consequently, equation (7) is reduced to

$$
M(x, t)=E I \frac{\partial \theta}{\partial x} \cos \theta \approx E I \frac{\partial \theta}{\partial x}\left(1-\frac{1}{2} \theta^{2}\right) .
$$

$\theta$ can be solved by methods of separating variable; the expression of $\theta$ is shown in

$$
\theta(x, t)=\Phi(x) \bar{\theta}(t),
$$

where $\Phi(x)$ represents the vibration shape function of porcelain pillar, and $\bar{\theta}(t)$ is the rotational angle of flange connection.

When the height of the cemented part is $h$, the bending moment provided by the flange is 


$$
\begin{gathered}
M=M(h, t)=E I \Phi^{\prime}(h) \bar{\theta}(t)\left(1-\frac{1}{2} \Phi^{2}(h) \bar{\theta}^{2}(t)\right) \\
\begin{array}{c}
\text { Let } k=E I \Phi^{\prime}(h), \eta=-(1 / 2) \Phi^{2}(h) ; \text { then, } \\
M=k\left[\bar{\theta}(t)+\eta \bar{\theta}^{3}(t)\right]
\end{array}
\end{gathered}
$$

Referring to equation (12), equation (4) is rewritten as follows after considering the nonlinear factors:

$$
M_{i}=k_{i}\left[\left(\theta_{i}-\theta_{i-1}\right)+\eta\left(\theta_{i}-\theta_{i-1}\right)^{3}\right] .
$$

In equation (13), the parameter $\eta$ is the nonlinear rigidity parameter combined with discontinuous deformation at the flange when subjected to large deformation. It is closely related to the vibration shape function of porcelain pillar assembly. It is difficult to get through a theoretical solution, so the value of $\eta$ is based on an experimental solution. When $\eta=0$, equation (13) is used to calculate the rotational bending moment under the ideal conditions represented by

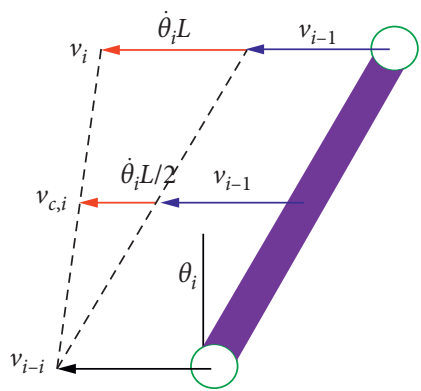

FIGURE 7: Speed relationship diagram of porcelain pillars.

equation (4). The different values of $\eta$ correspond to different degrees of the nonlinearity of the flange cemented part.

If there are $N_{c}$ porcelain pillars, there will be $N_{c}$ flange connections. The elastic potential energy at a flange connection is calculated as follows:

$$
U_{k}=\frac{1}{2} k_{1} \theta_{1}^{2}+\frac{1}{4} \eta k_{1} \theta_{1}^{4}+\sum_{i=2}^{N_{c}}\left[\frac{1}{2} k_{i}\left(\theta_{i}-\theta_{i-1}\right)^{2}+\frac{1}{4} \eta k_{i}\left(\theta_{i}-\theta_{i-1}\right)^{4}\right] .
$$

Since the rotation of porcelain pillars causes the change of gravitational potential energy of porcelain pillars, the total gravitational potential energy is calculated as follows:

$$
U_{g}=-\frac{1}{2} \sum_{i=1}^{N c} m_{i} g\left(\sum_{j=1}^{i} L_{j} \theta_{j}^{2}-\mid \frac{1}{2} L_{i} \theta_{i}^{2}\right)
$$

in which $L_{j}$ represents the length of $j^{\text {th }}$ porcelain pillar.

The kinetic energy of porcelain pillars consists of average kinetic energy and rotational kinetic energy:

$$
T=\frac{1}{2} \sum_{i=1}^{N_{c}} m_{i} v_{c, i}^{2}+\frac{1}{2} \sum_{i=1}^{N_{c}} \frac{1}{12} m_{i} L_{i}^{2} \dot{\theta}_{i}^{2}
$$

in which $v_{c, i}$ is the centroid velocity of the $i^{\text {th }}$ porcelain pillar, and $m_{i}$ is the mass of the $i^{\text {th }}$ porcelain pillar. For the four-section porcelain pillar system, the speed relationship of the $i^{\text {th }}$ porcelain pillar is illustrated in Figure 7:

As illustrated in Figure 7, the velocity of $1^{\text {st }}$ porcelain pillar bottom is

$$
v_{0}=\dot{x}_{b}
$$

The centroid velocity of the $1^{\text {st }}$ porcelain pillar is calculated as follows:

$$
v_{c, 1}=\frac{1}{2} L_{1} \dot{\theta}_{1}
$$

The centroid velocity of the $2^{\text {nd }}$ porcelain pillar is calculated as follows:

$$
v_{c, 2}=L_{1} \dot{\theta}_{1}+\frac{1}{2} L_{2} \dot{\theta}_{2}
$$

The centroid velocity of the $3^{\text {rd }}$ porcelain pillar is calculated as follows:

$$
v_{c, 3}=L_{1} \dot{\theta}_{1}+L_{2} \dot{\theta}_{2}+\frac{1}{2} L_{3} \dot{\theta}_{3} .
$$

The centroid velocity of the $4^{\text {th }}$ porcelain pillar is calculated as follows:

$$
v_{c, 4}=L_{1} \dot{\theta}_{1}+L_{2} \dot{\theta}_{2}+L_{3} \dot{\theta}_{3}+\frac{1}{2} L_{4} \dot{\theta}_{4}
$$

The Hamilton variational equation [28] is as follows:

$$
\int_{t_{1}}^{t_{2}}(\delta T-\delta U) \mathrm{d} t=0 .
$$

In equation (21), $U=U_{k}+U_{g}$. Then, 


$$
\begin{aligned}
\delta T= & -\sum_{i=1}^{N_{c}}\left[m_{i}\left(\ddot{x}_{b}+\sum_{j-1}^{i} L_{i} \ddot{\theta}_{i}\right) \delta\left(\sum_{j=1}^{i} L_{j} \theta_{j}-\frac{1}{2} L_{i} \theta_{i}\right)+\frac{1}{12} m_{i} L_{i}^{2} \ddot{\theta} \delta \theta_{i}\right], \\
\delta U= & \left(k_{1} \theta_{1}+k_{1} \eta \theta_{1}^{3}\right) \delta \theta_{1}-\sum_{i=1}^{N_{c}} m_{i} g\left(\sum_{j=1}^{i} L_{j} \theta_{j} \delta \theta_{j}-\frac{1}{2} L_{i} \theta_{i} \delta \theta_{i}\right) \\
& +\sum_{i=2}^{N_{c}}\left[k_{i}\left(\theta_{i}-\theta_{i-1}\right)+k_{i} \eta\left(\theta_{i}-\theta_{i-1}\right)^{3}\right] \delta\left(\theta_{i}-\theta_{i-1}\right) .
\end{aligned}
$$

After equations (23) and (24) are substituted into equation (22) and further simplification, equation (22) is rewritten in matrix form as follows:

$$
\mathbf{M} \ddot{\theta}+\mathbf{k} \boldsymbol{\theta}+\mathbf{N}(\theta)=\mathbf{F} \ddot{x}_{b},
$$

where

$$
\begin{aligned}
& \mathbf{M}=\left[\begin{array}{llll}
M_{11} & M_{12} & M_{13} & M_{14} \\
M_{21} & M_{22} & M_{23} & M_{24} \\
M_{31} & M_{32} & M_{33} & M_{34} \\
M_{41} & M_{42} & M_{43} & M_{44}
\end{array}\right], \\
& \mathbf{K}=\left[\begin{array}{cccc}
K_{11} & -k_{2} & 0 & 0 \\
-k_{2} & K_{22} & -k_{3} & 0 \\
0 & -k_{3} & K_{33} & -k_{4} \\
0 & 0 & -k_{4} & K_{44}
\end{array}\right] \\
& \mathbf{N}(\boldsymbol{\theta})=\left[\begin{array}{c}
k_{1} \eta_{1}\left(\theta_{1}-\theta_{0}\right)^{3}-k_{2} \eta_{2}\left(\theta_{2}-\theta_{1}\right)^{3} \\
k_{2} \eta_{2}\left(\theta_{2}-\theta_{0}\right)^{3}-k_{3} \eta_{3}\left(\theta_{3}-\theta_{2}\right)^{3} \\
k_{3} \eta_{3}\left(\theta_{3}-\theta_{2}\right)^{3}-k_{4} \eta_{4}\left(\theta_{4}-\theta_{3}\right)^{3} \\
k_{4} \eta_{4}\left(\theta_{4}-\theta_{3}\right)^{3}
\end{array}\right], \\
& F=-f\left[\begin{array}{c}
\left(\frac{1}{2} m_{1}+\sum_{i-2}^{4} m_{i}\right) L_{1} \\
\left(\frac{1}{2} m_{2}+\sum_{i-3}^{4} m_{i}\right) L_{2} \\
\left(\frac{1}{2} m_{3}+m_{4}\right) L_{3} \\
\frac{1}{2} m_{4} L_{4}
\end{array}\right] .
\end{aligned}
$$

In addition,

$$
\begin{aligned}
\theta & =\left\{\begin{array}{llll}
\theta_{1} & \theta_{2} & \theta_{3} & \theta_{4}
\end{array}\right\}^{T}, \\
M_{11} & =\left(\frac{1}{3} m_{1}+\sum_{i=2}^{4} m_{i}\right) L_{1}^{2},
\end{aligned}
$$$$
M_{12}=M_{21}=\left(\frac{1}{2} m_{2}+\sum_{i=3}^{4} m_{i}\right) L_{1} L_{2} \text {, }
$$$$
M_{13}=M_{31}=\left(\frac{1}{2} m_{3}+m_{4}\right) L_{1} L_{3} \text {, }
$$$$
M_{14}=M_{41}=\frac{1}{2} m_{4} L_{1} L_{4} \text {, }
$$$$
M_{22}=\left(\frac{1}{3} m_{2}+\sum_{i=3}^{4} m_{i}\right) L_{2}^{2}
$$$$
M_{23}=M_{32}=\left(\frac{1}{2} m_{3}+m_{4}\right) L_{2} L_{3} \text {, }
$$$$
M_{24}=M_{42}=\frac{1}{2} m_{4} L_{2} L_{4} \text {, }
$$$$
M_{33}=\left(\frac{1}{3} m_{3}+m_{4}\right) L_{3}^{2} \text {, }
$$$$
M_{34}=M_{43}=\frac{1}{2} m_{4} L_{3} L_{4},
$$$$
M_{44}=\frac{1}{3} m_{4} L_{4}^{2},
$$$$
K_{11}=k_{1}+k_{2}-\left(\frac{1}{2} m_{1}+\sum_{i=2}^{4} m_{i}\right) g L_{1}
$$$$
K_{22}=k_{2}+k_{3}-\left(\frac{1}{2} m_{2}+\sum_{i=3}^{4} m_{i}\right) g L_{2}
$$$$
K_{33}=k_{3}+k_{4}-\left(\frac{1}{2} m_{3}+m_{4}\right) g L_{3} K_{44}=k_{4}-\frac{1}{2} m_{4} g L_{4} \text {. }
$$ 


\section{Dynamic Response of Porcelain Pillar Electrical Equipment under Seismic Excitation}

3.1. Shaking Table Test. In this section, the accuracy and effectiveness of the proposed modeling method will be validated and demonstrated by comparing the analysis results with the experimental results.

The shaking table test set-up of a $1000 \mathrm{kV}$ porcelain surge arrester is shown in Figure 8(a). This equipment contains 4 insulators with a similar configuration. The mass, dimension, and material parameters are listed in Table 1.

In the shaking table tests, the strain gauges were placed in the $X$ direction of the root of each section of the casing (two on the opposite side); the accelerometer is placed in the $X$ direction of the top of the vibrating table and the top of each section of the casing, which is shown in Figure 8(b).

The amplitudes of the input artificial waves are $0.1 \mathrm{~g}$, $0.15 \mathrm{~g}, 0.2 \mathrm{~g}$, and $0.3 \mathrm{~g}$, and the direction of the input artificial wave is a single $X$ direction (refer to Figure 8(b)). Figure 9 shows the input seismic wave of the artificial ground motions, a broad resonant period range from $0.1 \mathrm{~s}$ to $0.9 \mathrm{~s}$, and the stress responses at the bottom with peak ground acceleration of $0.15 \mathrm{~g}$. The vibration table test obtains the strain at the bottom end of the porcelain pillar. The stress can be obtained by multiplying the elastic modulus of the porcelain bushing $(110 \mathrm{GPa})$ by the strain. Figure $9(\mathrm{~b})$ shows the maximum stress at the bottom of porcelain.

As seen in Figure 9, the maximum acceleration of the ground is about $2.3 \mathrm{~m} / \mathrm{s}^{2}$ and the maximum stress at the bottom end of the porcelain pillar is $11.14 \mathrm{MPa}$. Figure 10 shows the results when the peak value of the input wave is $0.3 \mathrm{~g}$. As seen in Figure 10, the maximum acceleration of the ground is about $4 \mathrm{~m} / \mathrm{s}^{2}$ and the maximum stress at the bottom end of the porcelain pillar is $22.02 \mathrm{MPa}$.

3.2. Seismic Wave Input in Theoretical Analysis. The seismic wave data are those for artificial waves jointly proposed by China Electric Power Research Institute and China Earthquake Disaster Prevention Center. This artificial wave is fitted by the seismic acceleration response spectrum with a characteristic cycle of $0.9 \mathrm{~s}$ that can envelop the characteristic cycles of Category I Category III soil sites, and it is suitable for seismic design, test, and seismic performance evaluation of HV and UHV electrical equipment. The artificial wave time history and the fitting data for artificial wave response spectrum and target spectrum at a peak seismic acceleration of $1 \mathrm{~g}$ are illustrated in Figure 11.

The data $X_{b}$ can be fitted with a periodic function $\tilde{X}_{b}$ :

$$
\widetilde{X}_{b}=\sum_{n=1}^{N_{F}} a_{n} \cos \frac{2 \pi n t}{T}+b_{n} \sin \frac{2 \pi n t}{T}
$$

in which

$$
\begin{aligned}
& a_{n}=\frac{2}{T} \int_{0}^{T} X_{b} \cos \frac{2 \pi n t}{T} \mathrm{~d} t, \\
& b_{n}=\frac{2}{T} \int_{0}^{T} X_{b} \sin \frac{2 \pi n t}{T} \mathrm{~d} t .
\end{aligned}
$$

When the value of $N_{F}$ is 500 , the fitting result is illustrated in Figure 11. As seen from Figure 11, the blue fitting curve has a high matching degree with the black seismic wave curve.

3.3. Method Validation. In order to verify the correctness of the theoretical model, the numerical method was used to solve equation (25) with the fitting seismic wave proposed in Section 3.2, and the results were compared with the curve obtained by the shaking table test in Section 3.1.

Based on the calculation by the kinetic model established according to equation (25), the first-order frequency of the four-section porcelain pillar equipment is $2.28 \mathrm{~Hz}$, and the result obtained by shaking table test is $2.18 \mathrm{~Hz}$, so there is a difference of $4.6 \%$ between the test value and the theoretical value. It indicates that the theoretical analysis is correct.

Figure 12 is a comparison curve of stress time histories at the bottom end of the porcelain pillars obtained by theoretical analysis and vibration table test at $a=0.15 \mathrm{~g}, a=0.3 \mathrm{~g}$ respectively, when the value of nonlinear rigidity parameter $\eta$ is taken as 20,000 . The maximum stresses at the bottom of the $1^{\text {st }}$ section of the equipment obtained by test and theoretical analysis are $11.14 \mathrm{MPa}$ and $11.00 \mathrm{MPa}$, respectively, at $a=0.15 \mathrm{~g}$, indicating that the difference between maximum stress values is $1.2 \%$. The theoretical and test curves also show a similar change trend.

The maximum stresses at the bottom of the $1^{\text {st }}$ section of the equipment obtained by test and theoretical analysis are 22.02 $\mathrm{MPa}$ and 20.30 $\mathrm{MPa}$, respectively, at $a=0.3 \mathrm{~g}$, indicating that the difference between maximum stress values is 9.04\%. Seismic excitation usually has nonlinear characteristics. With the increase of seismic excitation, the nonlinear characteristics of the porcelain pillar become more significant, which leads to the fact that the difference between test and analytical value becomes larger.

Figure 13 shows a comparative diagram of maximum stresses at the bottom of the $2^{\text {nd }}$ section pillar. When the peak acceleration of the input seismic wave is $0.15 \mathrm{~g}$, the maximum value of the nonlinear theoretical result is $9.41 \mathrm{MPa}$ and the maximum value of the test is $9.6 \mathrm{MPa}$. The difference between them is $2.0 \%$. When the peak acceleration of the input seismic wave is $0.3 \mathrm{~g}$, the maximum value of the nonlinear theoretical result is $19.25 \mathrm{MPa}$ and the maximum value of the test is $21.00 \mathrm{MPa}$. The difference between them is $8.3 \%$. 


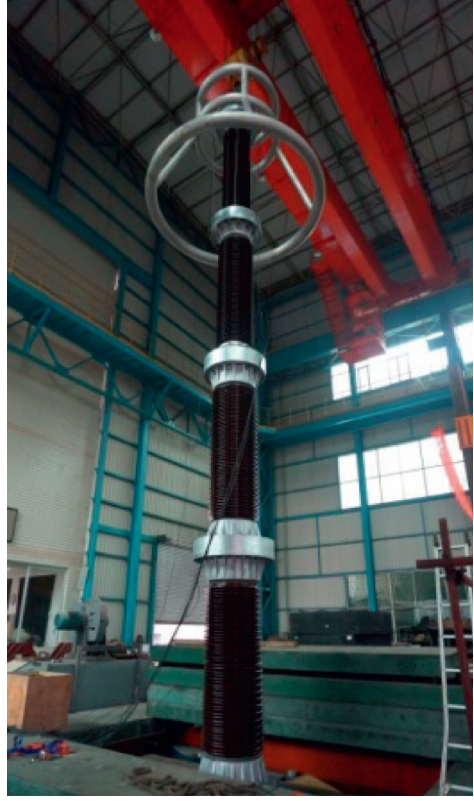

(a)

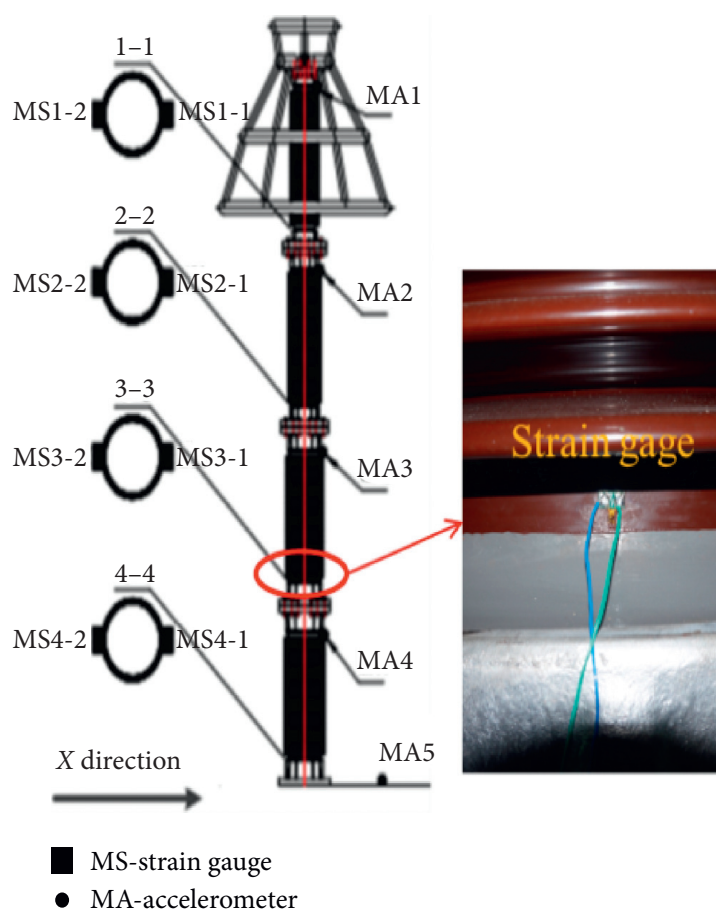

(b)

FIgUre 8: The diagram of the shaking table test. (a) Shaking table test set-up. (b) Sensor arrangement.

TABLE 1: Model parameters of insulators in a $1000 \mathrm{kV}$ porcelain surge arrester.

\begin{tabular}{cccccc}
\hline & Position of insulator unit & 1 & 2 & 3 & 4 \\
\hline & Mass of main body, $m(\mathrm{~kg})$ & 3413 & 2488 & 1938 & 1816 \\
Parameters & Length, $L(\mathrm{~m})$ & 2.912 & 2.755 & 2.855 & 1.811 \\
& Porcelain modulus, $E(\mathrm{~Pa})[29]$ & $1.1 \times 1011$ & $1.1 \times 1011$ & $1.1 \times 1011$ & $1.1 \times 1011$ \\
& Equivalent rigidity, $k(\mathrm{~N} / \mathrm{m})$ & $4.5 \times 108$ & $1.7 \times 108$ & $8.9 \times 107$ & $6.6 \times 107$ \\
& Inside/outside diameter $(\mathrm{mm})$ & $600 / 720$ & $550 / 650$ & $450 / 550$ & $380 / 450$ \\
\hline
\end{tabular}

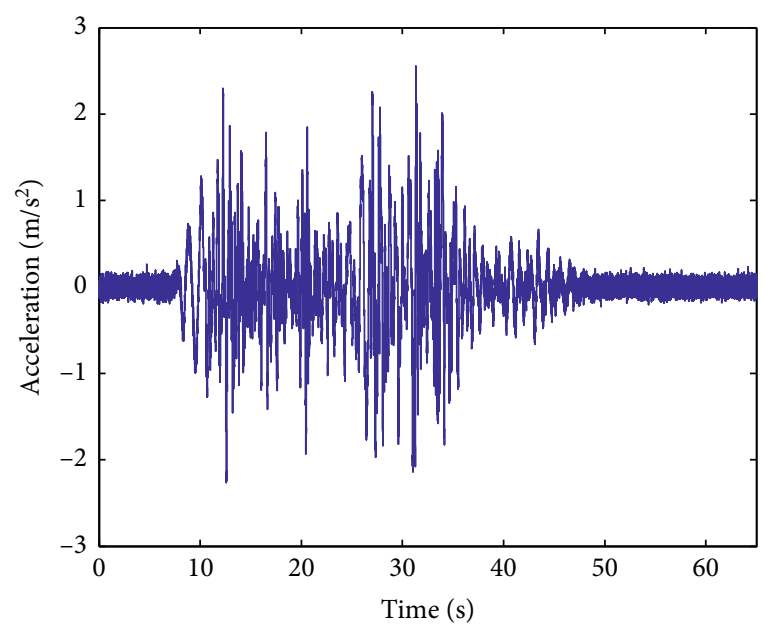

(a)

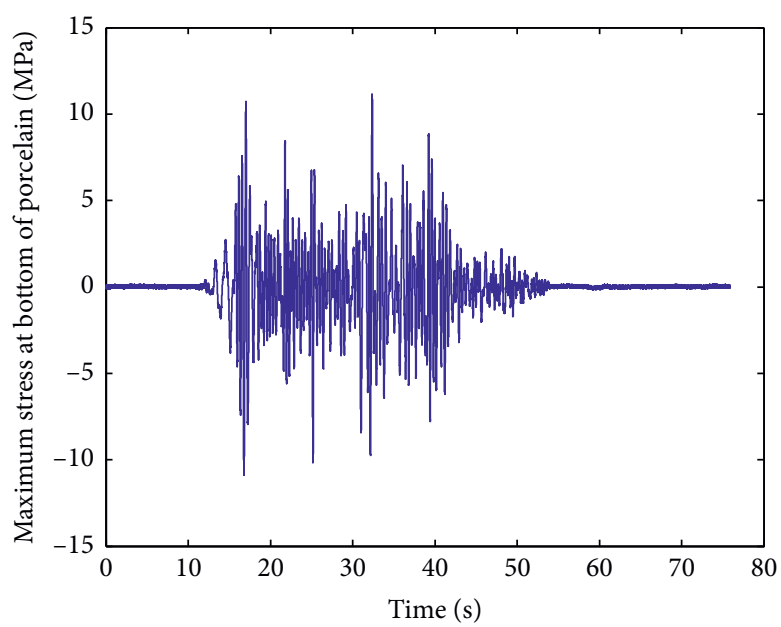

(b)

Figure 9: The waveform of shaking table test results $(0.15 \mathrm{~g})$. (a) Input acceleration time history (b) Stress responses at the bottom. 

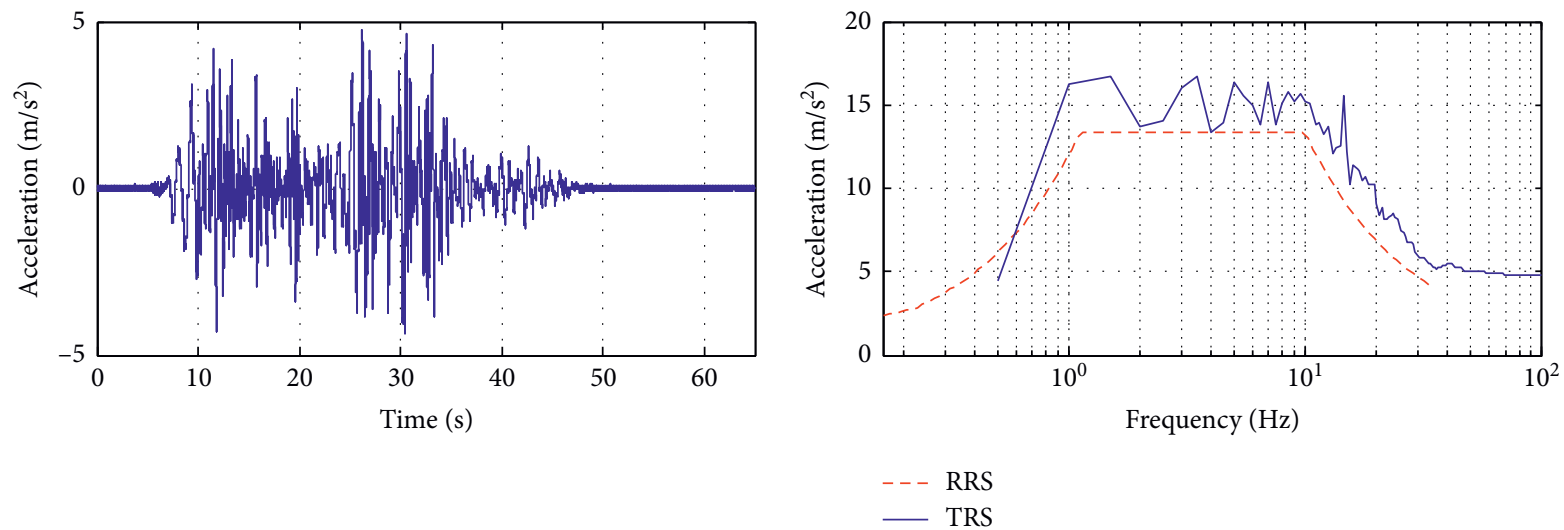

(a)

(b)

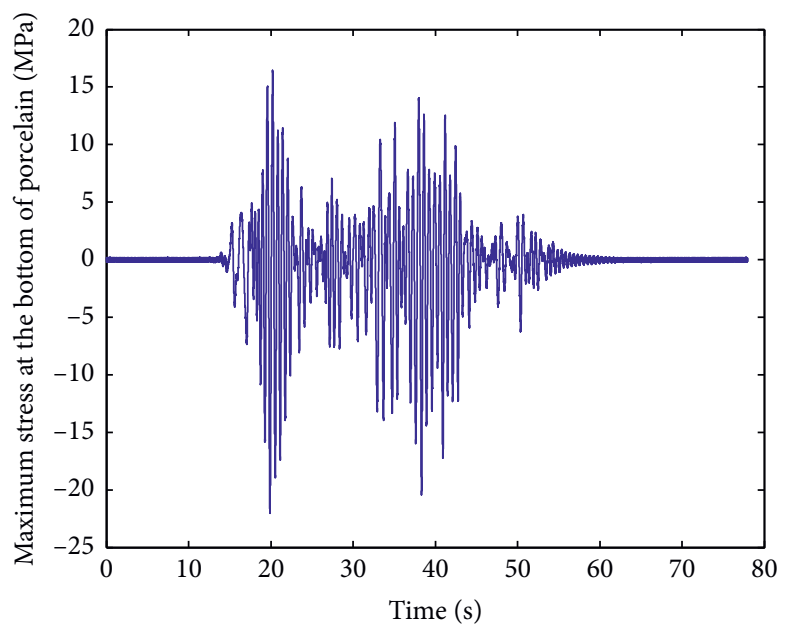

(c)

FIGURE 10: The waveform of shaking table test results ( $0.3 \mathrm{~g})$. (a) Input acceleration time history. (b) Response spectrum. (c) Stress responses at the bottom.

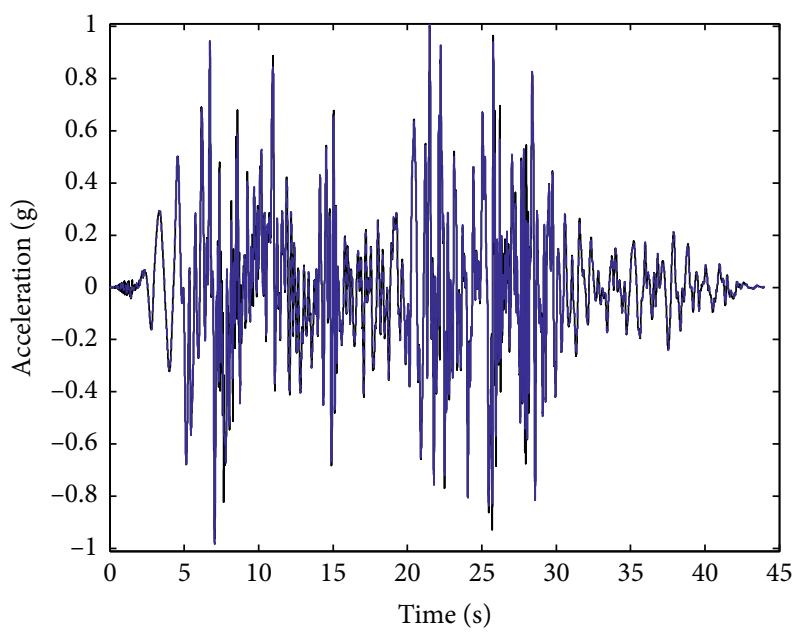

FIGURE 11: Fitted seismic wave by periodic function.

Through the above analysis, the theoretical calculation results have a rather high goodness of fit with the test results, thus verifying the correctness of the analytical model. When the value of $\eta$ is changed, new nonlinear theoretical analysis results are obtained. The differences between nonlinear analysis results and test results increase. According to the 


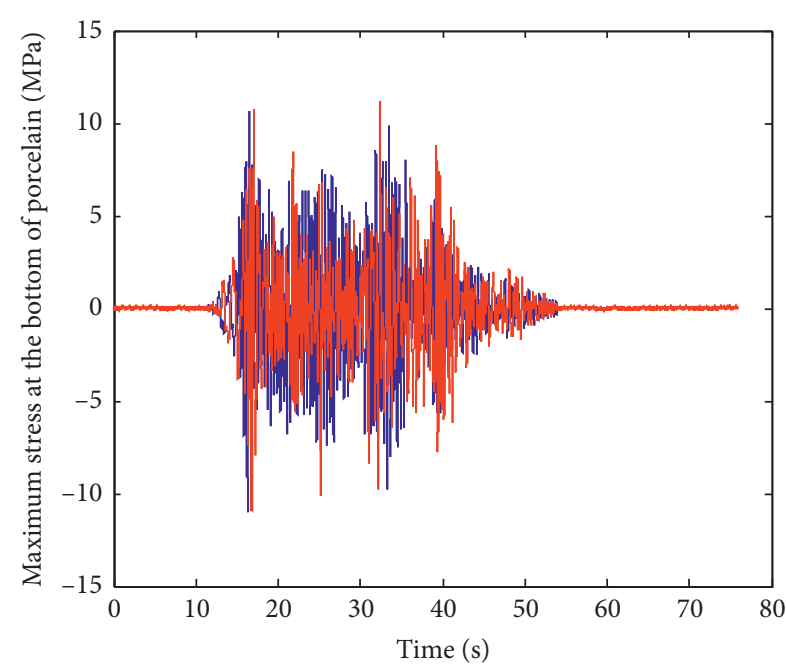

— Nonlinear theoretical analysis results - Test results

(a)

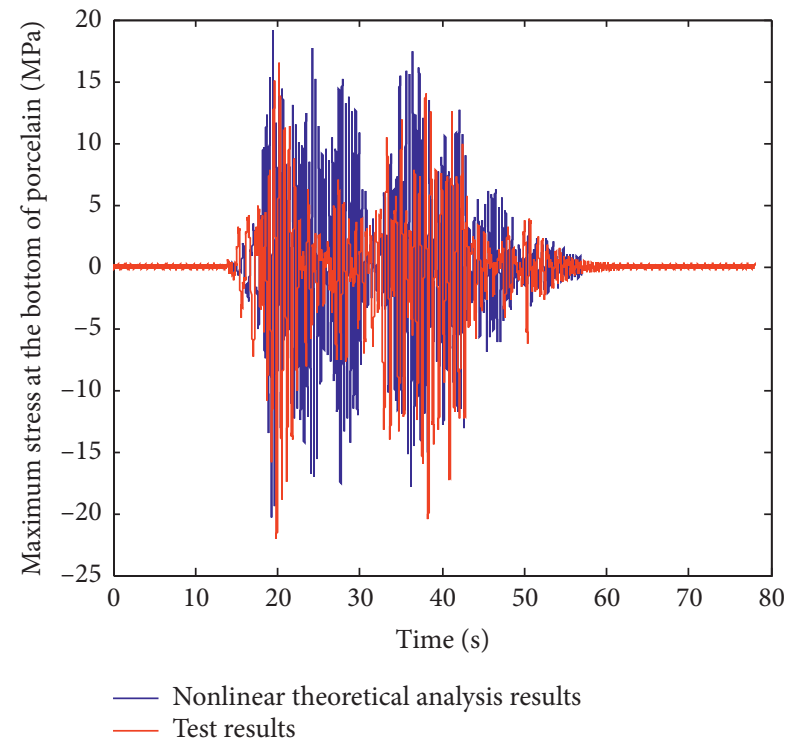

(b)

Figure 12: Comparative diagram of maximum stresses at the bottom end of porcelain pillars. (a) $0.15 \mathrm{~g}$. (b) $0.3 \mathrm{~g}$.

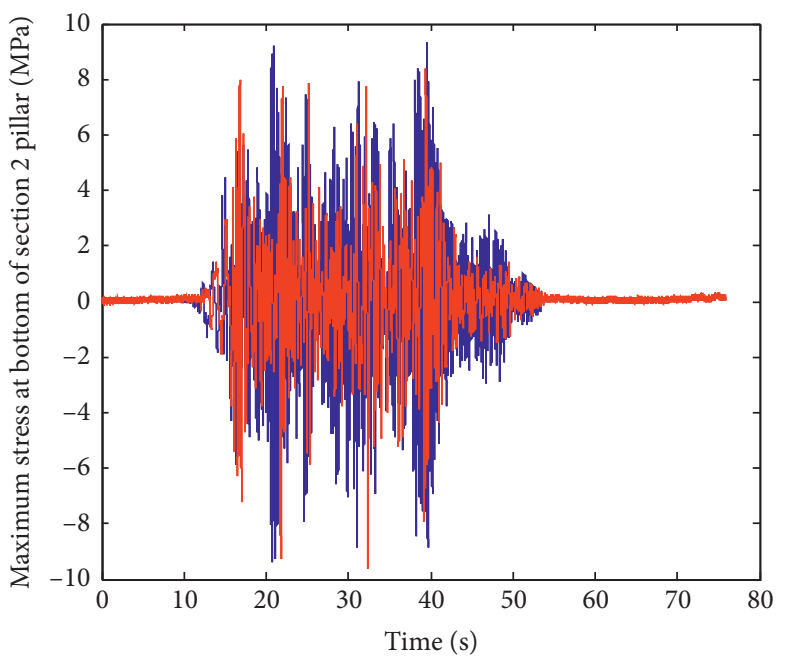

- Nonlinear theoretical analysis results _ Test results

pillar. (a)

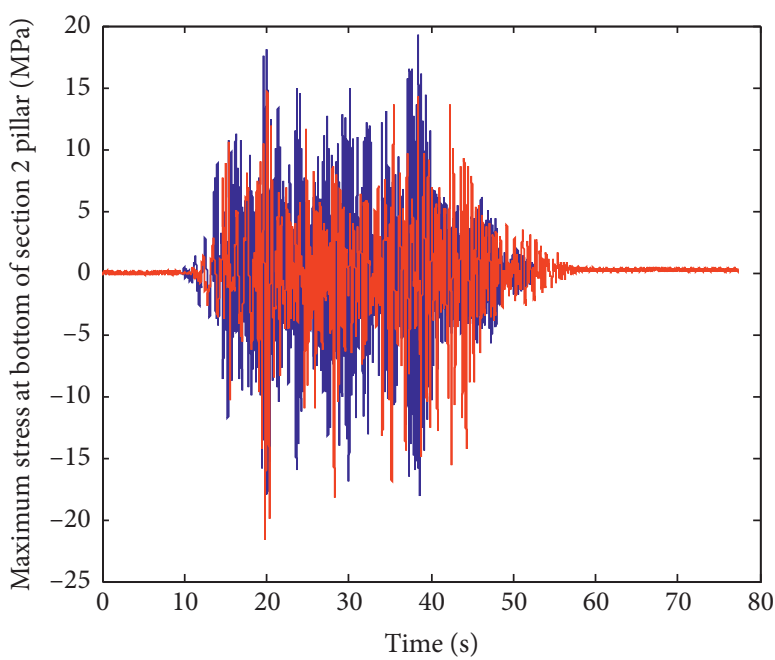

_ Nonlinear theoretical analysis results Test results

(b)

Figure 13: Comparative diagram of maximum stresses at the bottom of section 2 pillar. (a) $0.15 \mathrm{~g}$. (b) $0.3 \mathrm{~g}$.

comparison with the test results, it can be assumed that for the four-section porcelain pillar equipment, $\eta=20,000 \mathrm{can}$ reflect the nonlinear factors such as materials of cemented parts and large deformation in the actual applications.

\section{Seismic Response of $1,000 \mathrm{kV}$ Porcelain Pillar Arrester Equipment}

Equation (25) is solved to obtain the linear and nonlinear dynamic response of the $1,000 \mathrm{kV}$ arrester at $\eta=0$ and $\eta=20,000$, respectively. Figures 14-19 illustrate the curves of the displacement at the top end of the porcelain pillar and the maximum stress at the bottom end of the porcelain pillar under different seismic excitations with the linear values used. Figures 20-25 illustrate the curves of the displacement at the top end of the porcelain pillar and the maximum stress at the bottom end of the porcelain pillar under different seismic excitations with the nonlinear values used. From Figures 14-25, the maximum stresses and displacements of the porcelain pillar with linear and nonlinear conditions can 


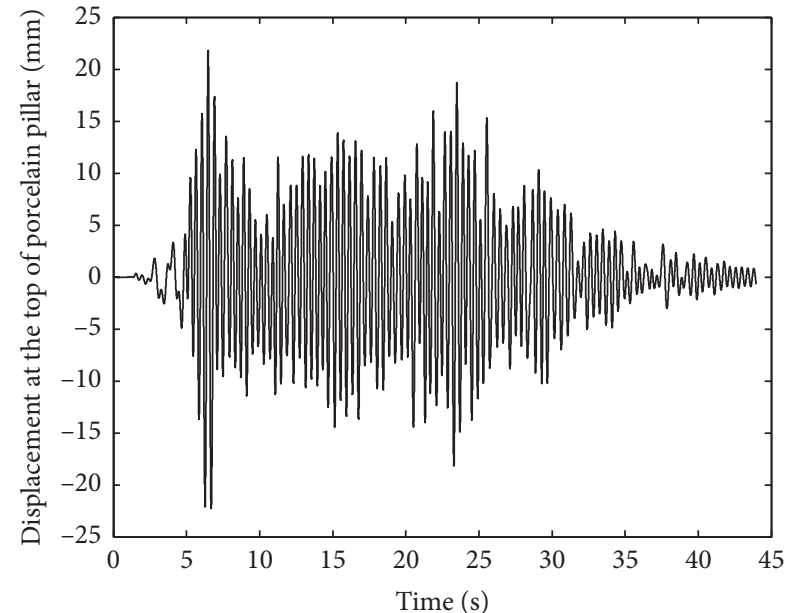

FIGURE 14: Displacement at the top of porcelain pillar $(a=0.1 \mathrm{~g}$, $\eta=0)$.

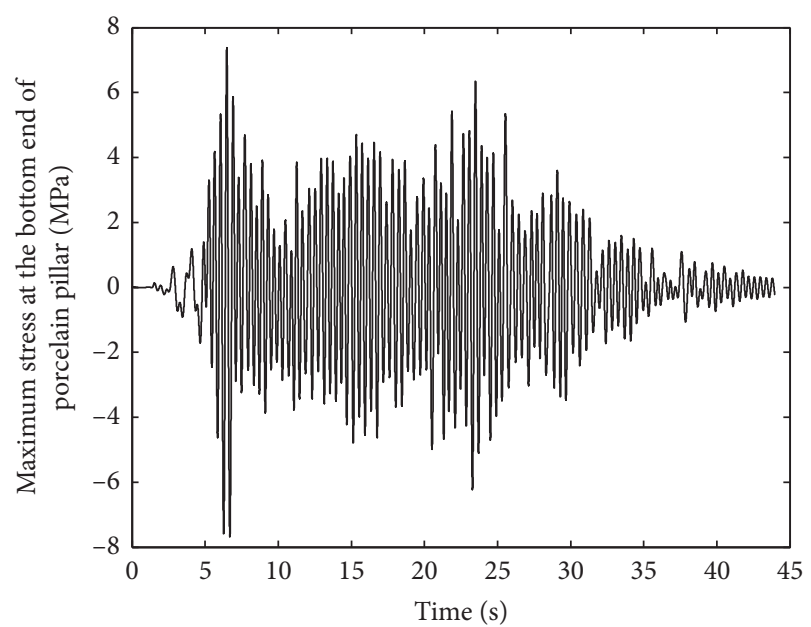

Figure 15: Maximum stress at the bottom of porcelain pillar $(a=0.1 \mathrm{~g}, \eta=0)$.

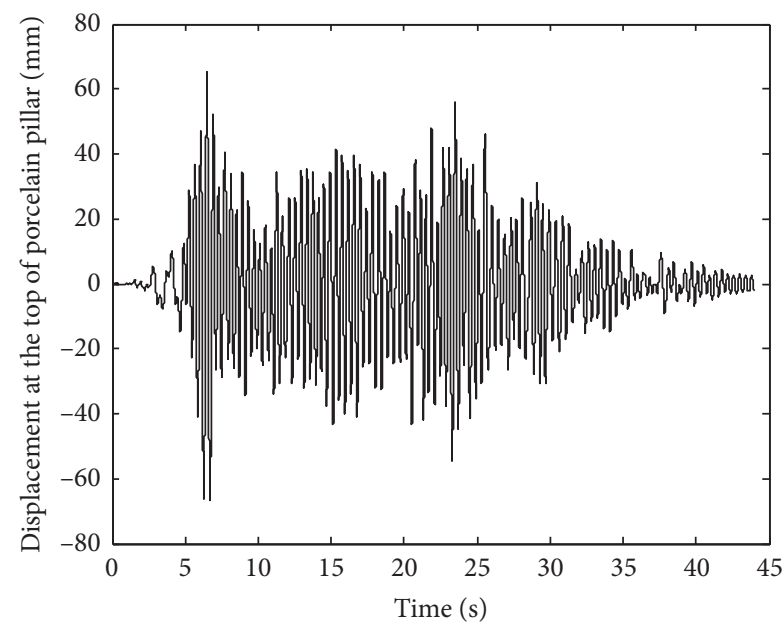

FIGURE 16: Displacement at the top of porcelain pillar $(a=0.3 \mathrm{~g}$, $\eta=0)$.

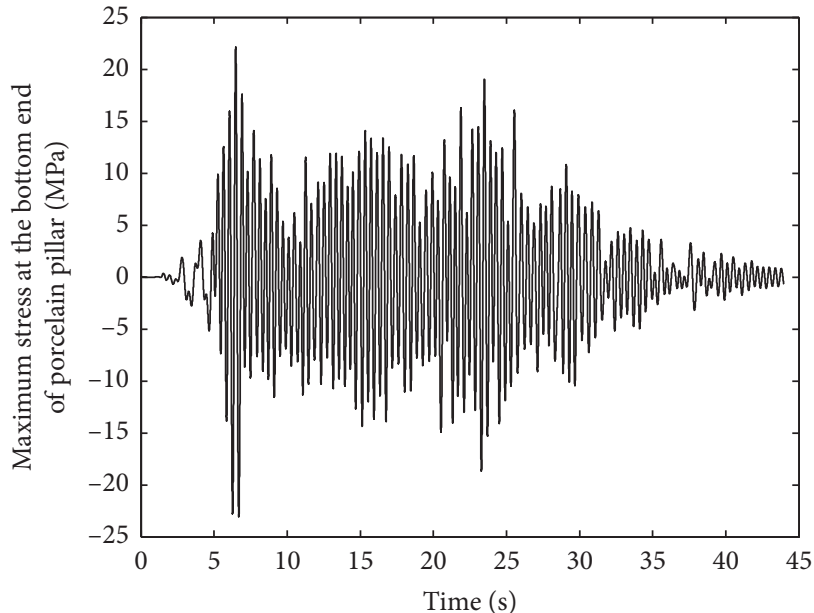

FIgURE 17: Maximum stress at the bottom of porcelain pillar $(a=0.3 \mathrm{~g}, \eta=0)$.

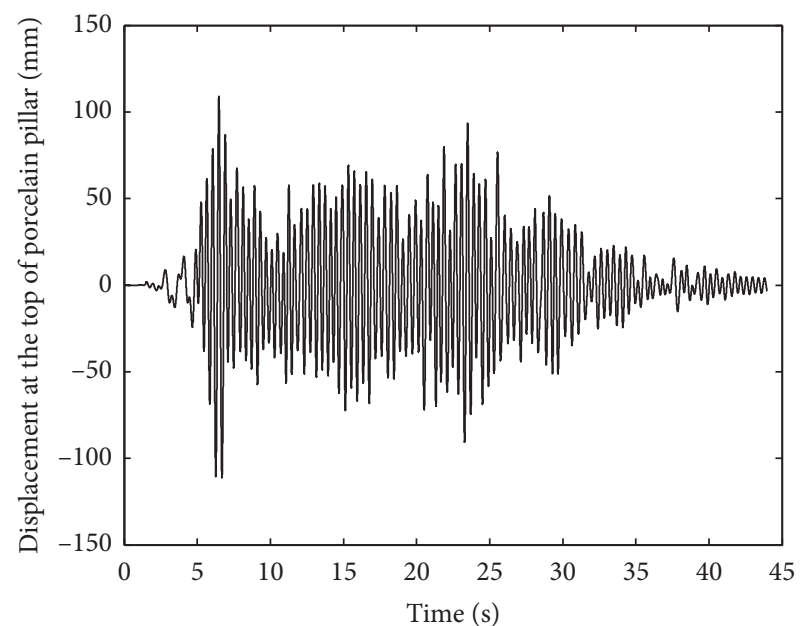

FIGURE 18: Displacement at the top of porcelain pillar $(a=0.5 \mathrm{~g}$, $\eta=0)$.

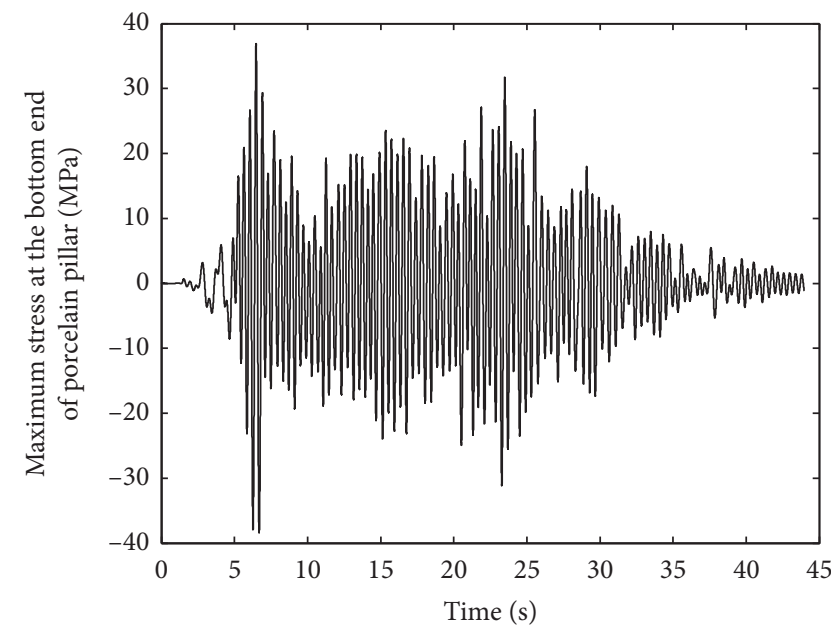

FIgURE 19: Maximum stress at the bottom of porcelain pillar $(a=0.5 \mathrm{~g}, \eta=0)$. 


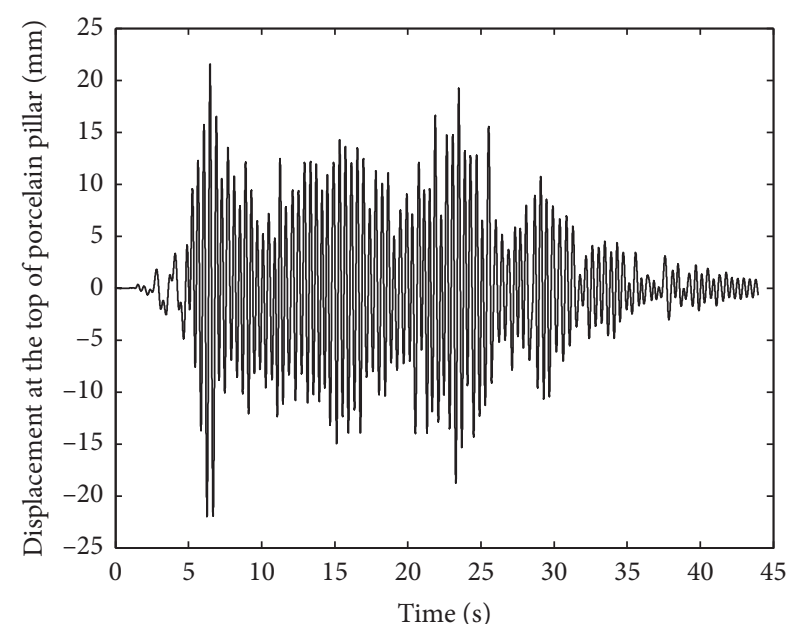

FIgURE 20: Displacement at the top of porcelain pillar $(a=0.1 \mathrm{~g}$, $\eta=20,000)$.

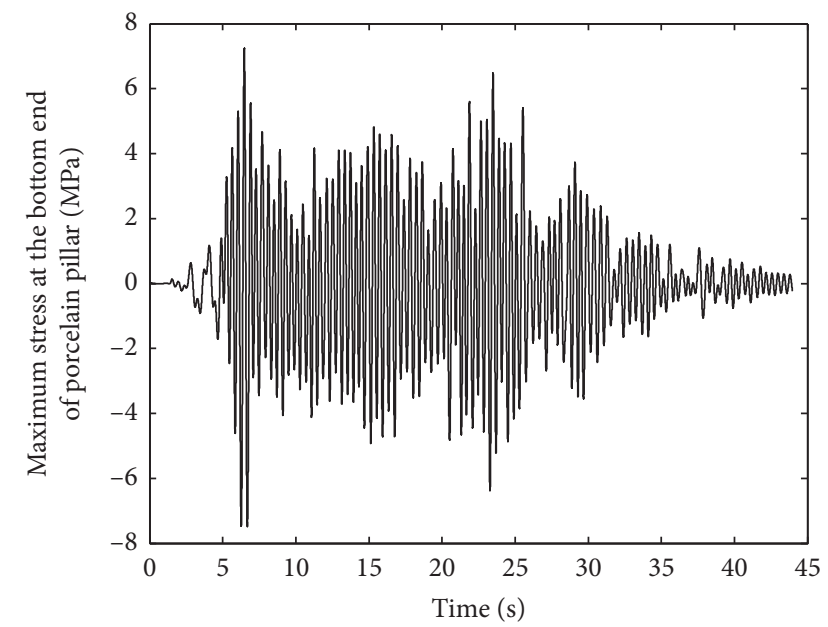

FIgURE 21: Maximum stress at the bottom of porcelain pillar $(a=0.1 \mathrm{~g}, \eta=20,000)$.

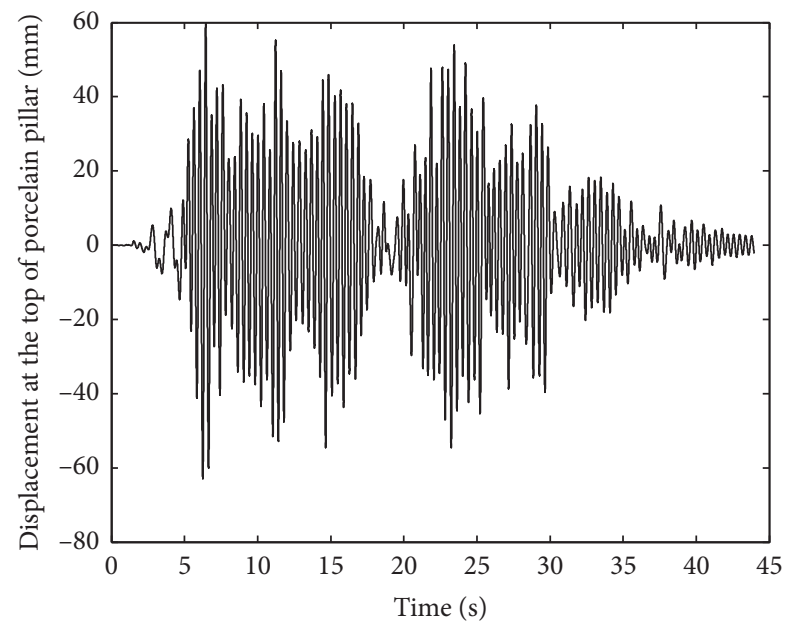

FIGURE 22: Displacement at the top of porcelain pillar $(a=0.3 \mathrm{~g}$, $\eta=20,000)$.

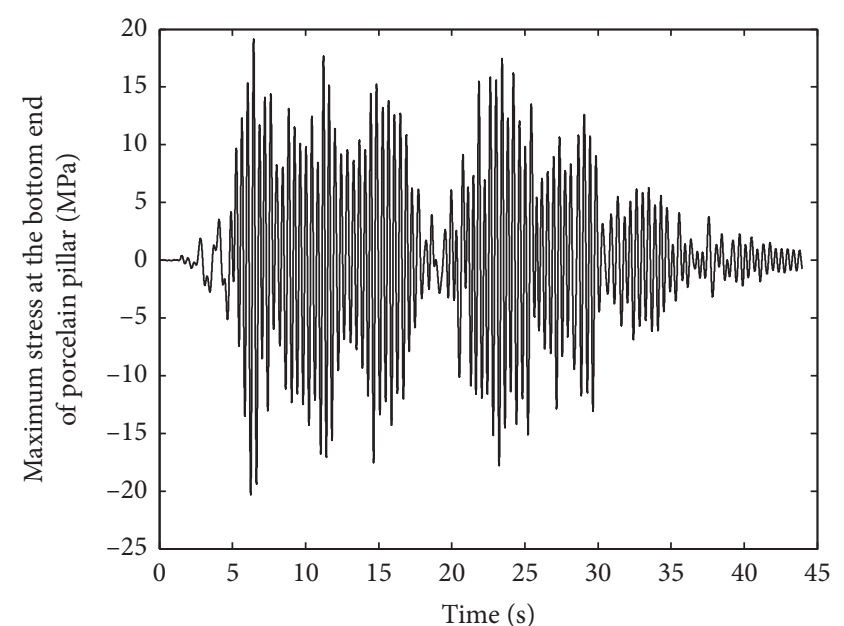

FIgURE 23: Maximum stress at the bottom of porcelain pillar $(a=0.3 \mathrm{~g}, \eta=20,000)$.

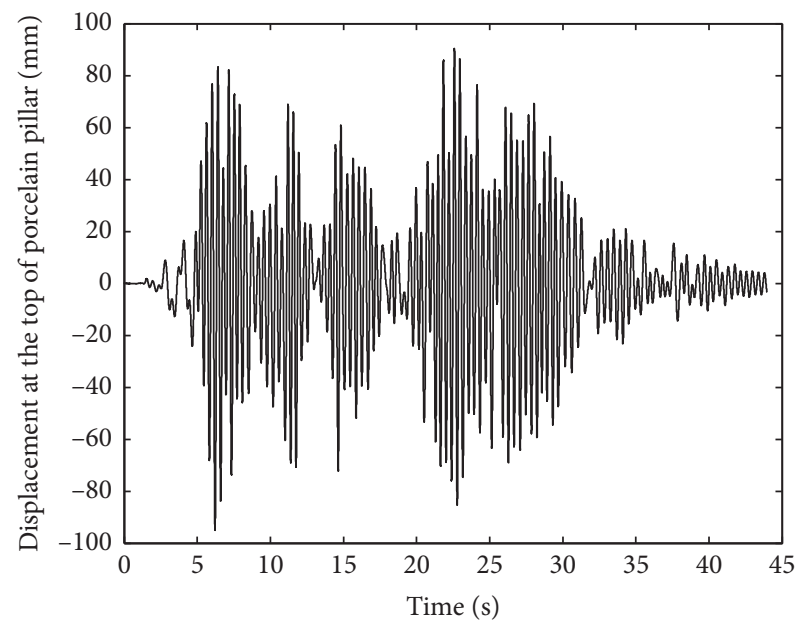

Figure 24: Displacement at the top of porcelain pillar $(a=0.5 \mathrm{~g}$, $\eta=20,000)$.

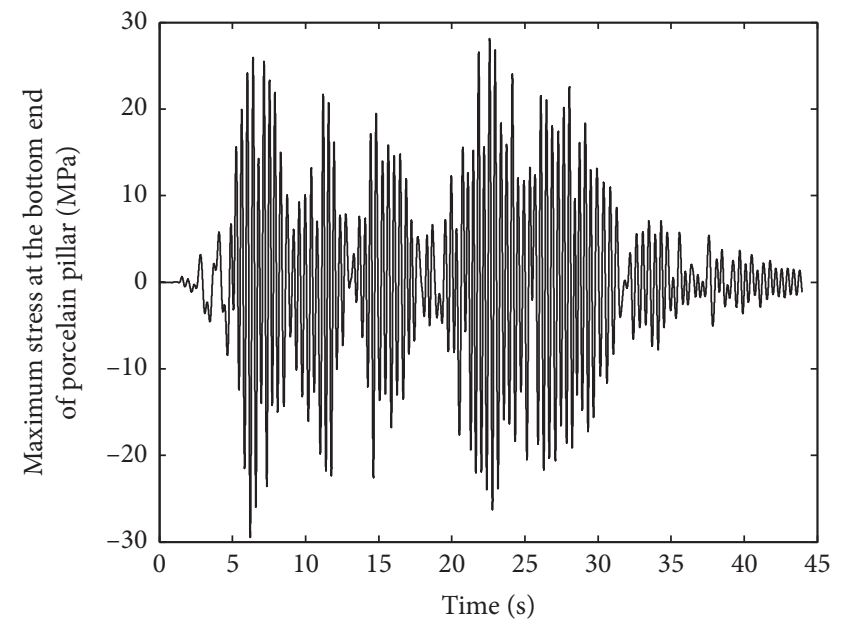

Figure 25: Maximum stress at the bottom of porcelain pillar $(a=0.5 \mathrm{~g}, \eta=20,000)$. 
be obtained, as shown in Table 2. Figure 26 illustrates the dynamic response of the equipment under different seismic excitations with the linear and nonlinear values used.

As seen from the analysis results in Table 2 and Figure 26, for the $1000 \mathrm{kV}$ arrester equipment, when the flange connection is linear, the maximum displacement and stress grow linearly with the increase of peak ground acceleration; when the nonlinear factor is considered, the maximum displacement and stress increase nonlinearly, and the magnitude of the increase gradually decreases. It can be seen from Figure 25 that the nonlinear seismic response of the equipment is smaller than the linear seismic response under seismic excitation. The greater the ground motion excitation, the larger the difference between nonlinear response results and linear response results of the equipment. It indicates that equipment exhibits more obvious nonlinear characteristics as seismic excitation increases.

When the peak ground acceleration increases from $0.1 \mathrm{~g}$ to $0.5 \mathrm{~g}$, the maximum displacement of the top of the porcelain pillar increases from $22.26 \mathrm{~mm}$ to $111.28 \mathrm{~mm}$ without consideration of nonlinear factor; when the nonlinear factor is considered, the range of this value is from $22 \mathrm{~mm}$ to $95.06 \mathrm{~mm}$. Correspondingly, the variation range of the maximum stress at the bottom end of the porcelain pillar is from $7.68 \mathrm{MPa}$ to $38.41 \mathrm{MPa}$ and $7.48 \mathrm{MPa}$ to $29.48 \mathrm{MPa}$, respectively. When the peak ground acceleration is $0.1 \mathrm{~g}$, $0.2 \mathrm{~g}, 0.3 \mathrm{~g}, 0.4 \mathrm{~g}$, and $0.5 \mathrm{~g}$, the percentages of the difference between nonlinear analysis results and linear analysis results of displacement are $1.17 \%, 2.88 \%, 5.72 \%, 9.66 \%$, and $14.58 \%$ respectively, and the percentages of the difference between nonlinear analysis results and linear analysis results of stress are $2.60 \%, 6.77 \%, 11.93 \%, 17.51 \%$, and $23.25 \%$, respectively.

\section{Characteristics of Nonlinear Seismic Response within Structural Parameter Domains}

Figure 27 illustrates the curves for the influence of changes of nonlinear rigidity parameter within a certain range on the maximum stress at the bottom end of porcelain pillar when the seismic excitations are $0.1 \mathrm{~g}, 0.2 \mathrm{~g}, 0.3 \mathrm{~g}, 0.4 \mathrm{~g}$, and $0.5 \mathrm{~g}$. Table 3 shows the corresponding maximum stress value at the bottom end of the porcelain pillar with the change of nonlinear rigidity $\eta$ under different seismic excitations.
As seen from Figure 27, for different seismic excitations, as the nonlinear rigidity increases, the maximum stress at the bottom end of the porcelain pillar exhibits change characteristic of decreasing first and then becoming stable. When the seismic excitation is $0.1 \mathrm{~g}$ and the nonlinear rigidity is $12 \times 10^{4}$, the maximum stress at the bottom end of porcelain is $6.67 \mathrm{MPa}$, which has a decrease of about $9.5 \%$ compared with that when the nonlinear rigidity is 0 . The nonlinear rigidity change has a rather little impact on the maximum stress at the bottom end of the porcelain pillar. As seen from Table 3, the impact of nonlinear rigidity on the maximum stress at the bottom end of the porcelain pillar increases gradually when the seismic excitation increases. When the seismic excitation is $0.2 \mathrm{~g}, 0.3 \mathrm{~g}, 0.4 \mathrm{~g}$, and $0.5 \mathrm{~g}$, respectively, and the nonlinear rigidity is $12 \times 10^{4}$, the maximum stress at the bottom end of the porcelain pillar decreases by $23.8 \%$, $26.6 \%, 35.5 \%$, and $42.8 \%$ compared with that when the nonlinear rigidity is 0 .

According to Section 3.3, $\eta=20,000$ can reflect the nonlinear factors, and the maximum stress at the bottom end of the porcelain pillar is analyzed with $\eta$ changes in the range of $\left[0,4 \times 10^{4}\right]$ in order to consider the influence of fluctuation of $\eta$ on the maximum stress at the bottom end of porcelain pillar. When the seismic excitation is $0.1 \mathrm{~g}, 0.2 \mathrm{~g}$, $0.3 \mathrm{~g}, 0.4 \mathrm{~g}$, and $0.5 \mathrm{~g}$, respectively, and $\eta$ increases from 0 to $2 \times 10^{4}$, the maximum stress at the bottom end of the porcelain pillar decreases by $1.9 \%, 6.7 \%, 13.43 \%, 21.2 \%$, and 23.7\%; when $\eta$ increases from $2 \times 10^{4}$ to $4 \times 10^{4}$, the maximum stress at the bottom end of porcelain pillar decreases by $1.8 \%, 5.9 \%, 11.33 \%, 3.7 \%$, and $4.01 \%$, respectively. As seen from the above analysis, the decrease rate of the maximum stress at the bottom end of the porcelain pillar when $\eta$ increases from $2 \times 10^{4}$ to $4 \times 10^{4}$ is smaller than that when $\eta$ increases from 0 to $2 \times 10^{4}$.

As seen from Figure 27, as the seismic excitation increases, the nonlinear rigidity change ranges corresponding to rapid decrease stages of maximum stress at the bottom end of porcelain pillar are $\left[0,12 \times 10^{4}\right],\left[0,10 \times 10^{4}\right]$, $\left[0,8 \times 10^{4}\right],\left[0,4 \times 10^{4}\right]$, and $\left[0,2 \times 10^{4}\right]$, and the change ranges have a trend of gradual decrease. It indicates that the influence of nonlinear rigidity on the maximum stress at the bottom end of the porcelain pillar under high seismic excitation is larger and the maximum stress changes rapidly. When the nonlinear rigidity increases to a certain value, the impact of nonlinear rigidity on the maximum stress at the 
TABLE 2: Maximum stress and displacement of porcelain pillar.

\begin{tabular}{|c|c|c|c|c|}
\hline \multirow{2}{*}{ Seismic excitation $(\mathrm{g})$} & \multicolumn{2}{|c|}{ Maximum displacement (mm) } & \multicolumn{2}{|c|}{ Maximum stress $(\mathrm{MPa})$} \\
\hline & Linear & Nonlinear & Linear & Nonlinear \\
\hline 0.1 & 22.26 & 22 & 7.68 & 7.48 \\
\hline 0.2 & 44.51 & 43.23 & 15.37 & 14.33 \\
\hline 0.3 & 66.77 & 62.95 & 23.05 & 20.3 \\
\hline 0.4 & 89.02 & 80.42 & 30.73 & 25.35 \\
\hline 0.5 & 111.28 & 95.06 & 38.41 & 29.48 \\
\hline
\end{tabular}
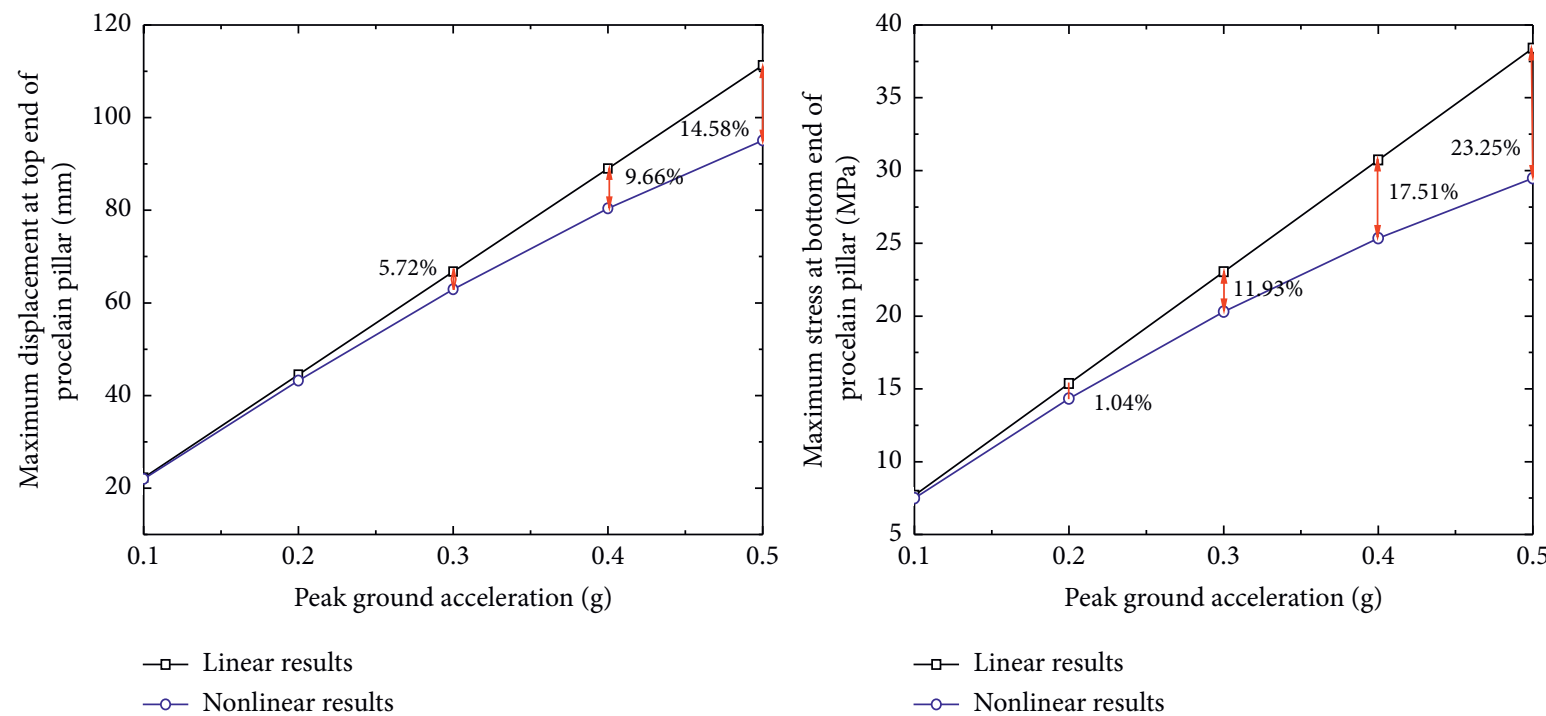

FIgURE 26: Curves of the relation between different seismic excitations and equipment dynamic response.

TABLe 3: Maximum stress value at the bottom end of porcelain pillar with the change of nonlinear rigidity under different seismic excitations.

\begin{tabular}{lcccccc}
\hline \multirow{2}{*}{ Seismic excitation (g) } & \multicolumn{5}{c}{ Maximum stress at the bottom end of porcelain pillar at the different values of $\eta /(\mathrm{MPa})$} \\
& 0 & $2 \times 10^{4}$ & $4 \times 10^{4}$ & $6 \times 10^{4}$ & $8 \times 10^{4}$ & $10 \times 10^{4}$ \\
\hline 0.1 & 7.37 & 7.23 & 7.10 & 7.00 & 6.88 & 6.77 \\
0.2 & 14.75 & 13.76 & 12.95 & 12.25 & 11.62 & 11.12 \\
0.3 & 22.12 & 19.15 & 16.98 & 16.90 & 16.46 & 16.61 \\
0.4 & 29.48 & 23.24 & 22.39 & 21.87 & 20.30 & 18.06 \\
0.5 & 36.86 & 28.13 & 27.00 & 24.62 & 25.35 & 16.24 \\
\hline
\end{tabular}

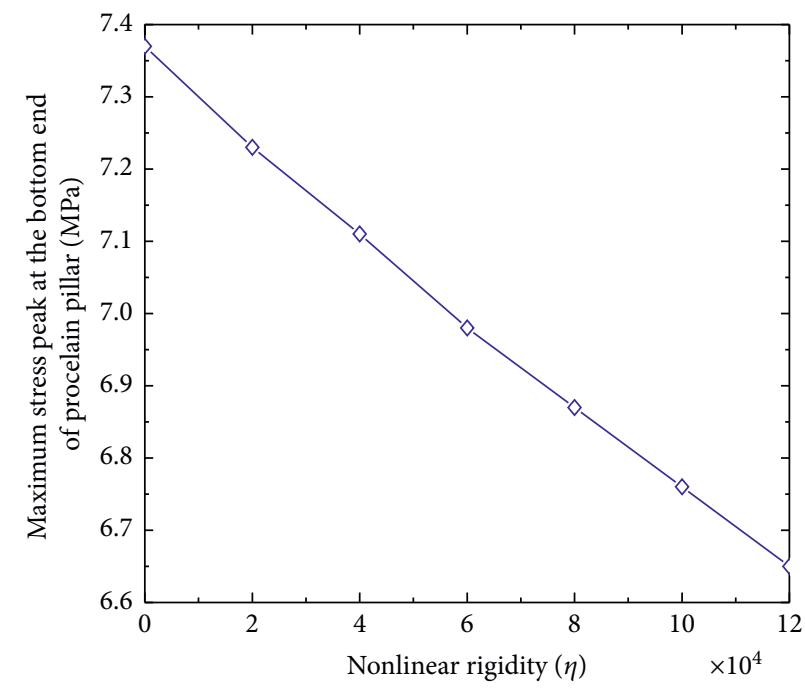

(a)

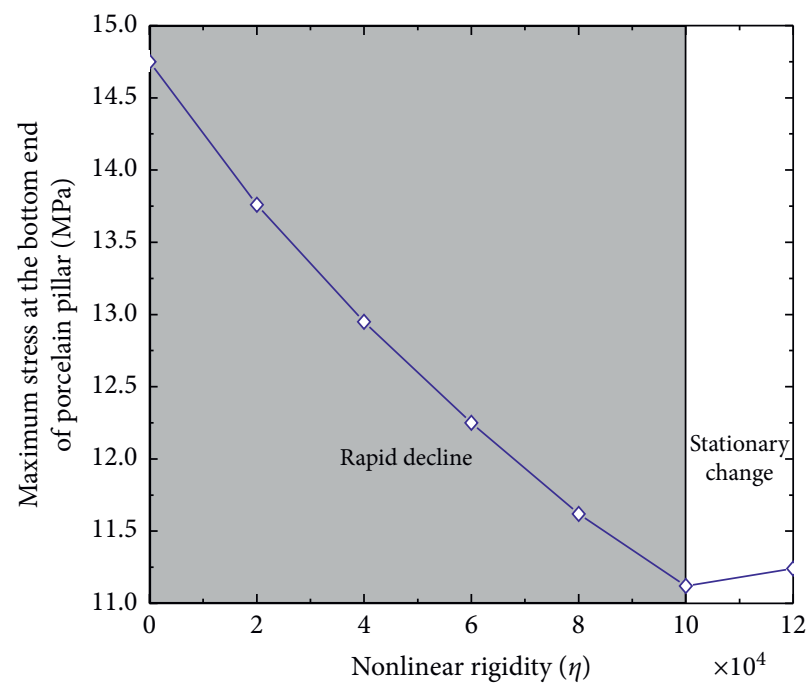

(b)

Figure 27: Continued. 


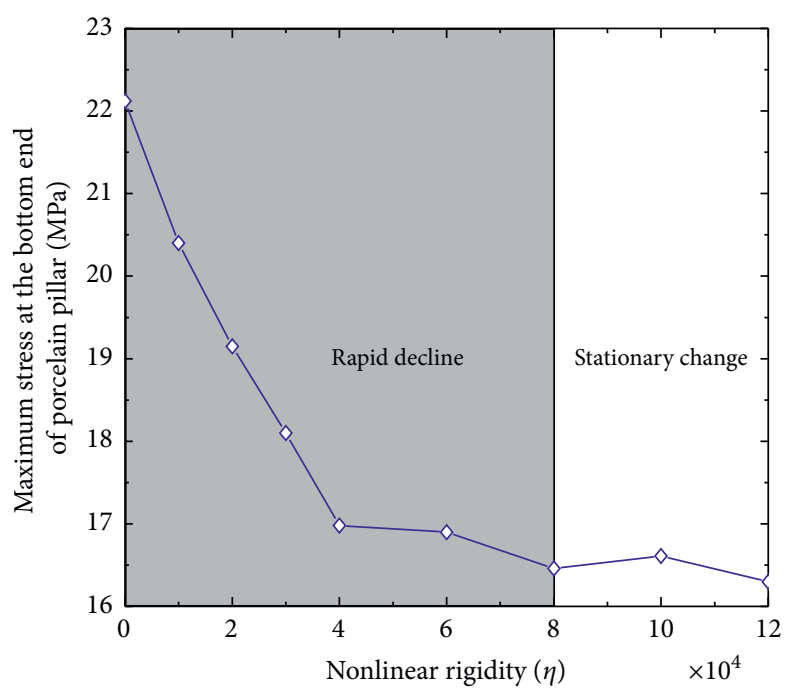

(c)

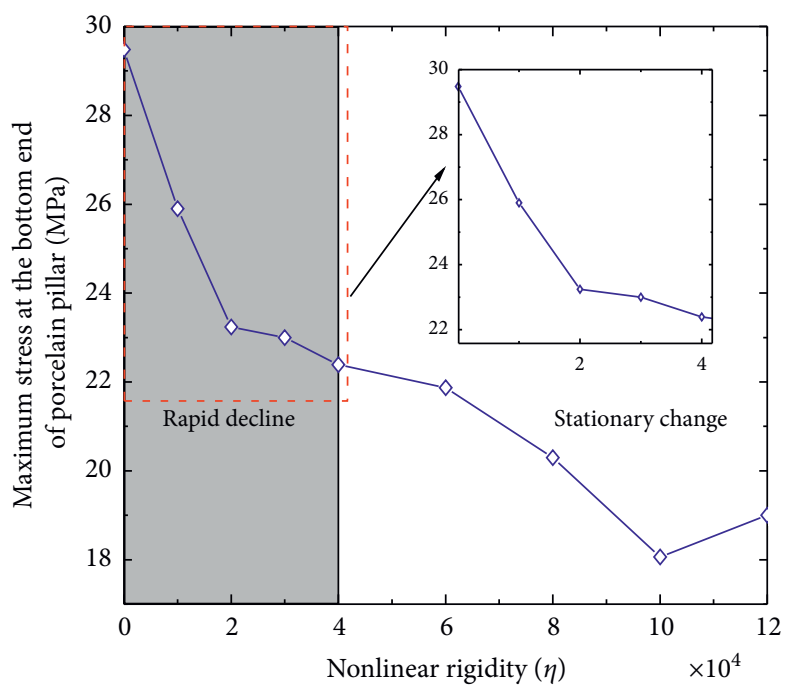

(d)

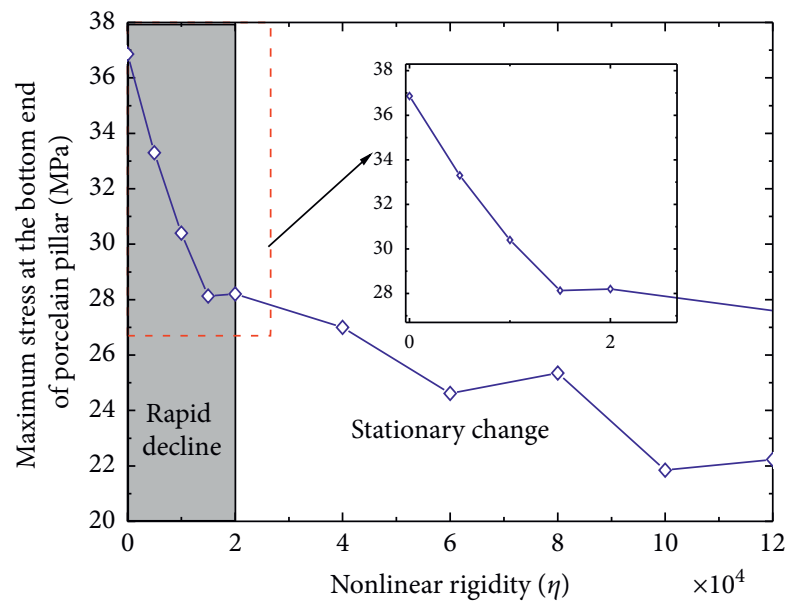

(e)

FIgURE 27: Curves of the relation between nonlinear rigidity parameter and maximum stress of equipment under different seismic excitations. (a) 0.1 g. (b) 0.2 g. (c) 0.3 g. (d) 0.4 g. (e) 0.5 g.

bottom end of the porcelain pillar is rather small, and the stress change of the porcelain pillar has entered stationary change.

\section{Conclusions}

(1) According to elastic mechanics, in the range of elasticity, it is assumed that the glued part of flange connection assembly before and after deformation follows the plain-section assumption; that is, the cross section after deformation at the glued part assembly is perpendicular to the neutral plane. A dynamic model of porcelain pillar electrical equipment was established for considering the nonlinear characteristics of flange connections. The theoretical analysis results and the test results have a rather good degree of the fitting, which verifies the correctness of the dynamic model. When the nonlinear rigidity parameter is 20,000 , the influence of nonlinear factors at the cementing parts can be reflected

(2) Both the nonlinear calculation results of the displacement at the top end of the porcelain pillar and the stress at the bottom end of the porcelain pillar are smaller than the linear calculation results. The difference between such two kinds of results increases gradually with the increase of seismic excitation. The differences in displacement and stress at a seismic excitation of $0.5 \mathrm{~g}$ are $14.58 \%$ and $23.25 \%$, respectively

(3) When the nonlinear rigidity increases to a certain value, the influence of nonlinear rigidity on the maximum stress at the bottom end of the porcelain pillar is rather small, the stress change of the porcelain pillar has entered stationary change. As the seismic excitation increases, the nonlinear rigidity change ranges corresponding to rapid decrease 
stages of maximum stress at the bottom end of the porcelain pillar decrease gradually

\section{Data Availability}

The data used to support the findings of this study are available from the corresponding author upon request.

\section{Conflicts of Interest}

The authors declare that they have no conflicts of interest.

\section{Acknowledgments}

This study was funded by the National Key R\&D Program of China (2018YFC0809400).

\section{References}

[1] S. Li, H.-H. Tsang, Y. Cheng, and Z. Lu, "Considering seismic interaction effects in designing steel supporting structure for surge arrester," Journal of Constructional Steel Research, vol. 132, pp. 151-163, 2017.

[2] S. Li, H. H. Tsang, Y. Cheng et al., "Effects of sheds and cemented joints on seismic modeling of cylindrical porcelain electrical equipment in substations," Earthquakes and Structures, vol. 12, no. 1, pp. 55-65, 2016.

[3] Q. Xie, "Field investigation on damage of substation equipment in Wenchuan earthquake," in Proceedings of the 2008 Workshop on Electrical System Earthquake Engineering, Berkeley, CA, USA, October 2008.

[4] Q. Xie, Y. F. Wang, and S. H. Wei, "Seismic failure analysis on substation equipment interconnected by flexible conductor," in Proceedings of the International Conference on Sustainable Power Generation \& Supply, IEEE, Nanjing, China, April 2009.

[5] D. C. Zhang, W. B. Zhao, and M. Y. Liu, Analysis on Seismic Disaster Damage Cases and Their Causes of Electric Power Equipment in 5.12 Wenchuan Earthquake, Journal of Nanjing University of Technology (Natural Science Edition), Nanjing, China, 2009.

[6] JEAG5003-1980, "Guidelines for seismic the design of electrical equipment in substation," 1980.

[7] IEEE Std. 693-2005, IEEE Recommended Practice for Seismic Design of SubstationsInstitute of Electrical and Electronics Engineers, Piscataway, NJ, USA, 2005.

[8] R. A. Larder, R. P. Gallagher, and B. Nilsson, "Innovative seismic design aspects of the intermountain power project converter stations," IEEE Transactions on Power Delivery, vol. 4, no. 3, pp. 1708-1714, 1989.

[9] M. Kawada, "Seismic Analysis and Test on Transformer bushing," in Proceedings of the International Conference on Large High Voltage Electric Systems, Paris, France, September 1984.

[10] X. S. Zhang, Z. B. Dai, Z. C. Lu et al., "Parameter of bending stiffness of interconnected parts between ultra-high voltage porcelain bushings and flanges," Engineering Journal of Wuhan University, vol. 47, no. 6, pp. 794-799, 2014, in Chinese.

[11] M. P. Singh, S. Singh, and E. E. Matheu, "A response spectrum approach for seismic performance evaluation of actively controlled structures," Earthquake Engineering \& Structural Dynamics, vol. 29, no. 7, pp. 1029-1051, 2000.
[12] A. S. Gilani, A. S. Whittaker, and G. L. Fenves, "Seismic evaluation and retrofit of $230-\mathrm{kV}$ porcelain transformer bushings," Earthquake Spectra, vol. 17, no. 4, pp. 597-616, 2001.

[13] A. Filiatrault and H. Matt, "Seismic response of high voltage electrical transformer-bushing systems," Journal of Structural Engineering, vol. 132, no. 2, pp. 287-295, 2006.

[14] J. Bender and A. Farid, "Seismic vulnerability of power transformer bushings," Engineering Structures, vol. 162, pp. 1-10, 2018.

[15] R. Villaverde, G. C. Pardoen, and S. Carnalla, "Ground motion amplification at flange level of bushings mounted on electric substation transformers," Earthquake Engineering \& Structural Dynamics, vol. 30, no. 5, pp. 621-632, 2001.

[16] A. J. Schiff, "Proposed change to IEEE qualification of transformers and their bushings," in Proceedings of the Technical Council on Lifeline Earthquake Engineering Conference, Oakland, CA, USA, July 2009.

[17] C. He, Q. Xie, Z. Yang et al., "Seismic evaluation and analysis of $1100 \mathrm{kV}$ UHV porcelain transformer bushings," Soil Dynamics and Earthquake Engineering, vol. 123, pp. 498-512, 2019.

[18] G. X. Cao, "Analysis and experimental research on the restoring force characteristics of insulator column," Xi'an University of Architecture and Technology, Xi'an, China, 2008, in Chinese.

[19] A. J. Schiff, R. E. Torres-Cabrejos, and J. T. P. Yao, "Evaluating the seismic reliability of electrical equipment containing ceramic structural members," Earthquake Engineering \& Structural Dynamics, vol. 7, no. 1, pp. 85-98, 2010.

[20] Y. Xia, J. Xu, D. Li et al., "Analysis of seismic performance for high-voltage Switchgear equipment of GIS," in Proceedings of the International Conference on Electric Power EquipmentSwitching Technology, IEEE, Busan, South Korea, October 2014.

[21] S. Günay and K. M. Mosalam, "Seismic performance evaluation of high-voltage disconnect switches using real-time hybrid simulation: II. parametric study," Earthquake Engineering \& Structural Dynamics, vol. 43, no. 8, pp. 1223-1237, 2014.

[22] S. Lin, Z. B. Lu, P. Gao, and S. Li, "Study of shaking table test on seismic performance of $750 \mathrm{kV}$ post insulator," Advanced Materials Research, vol. 1065-1069, pp. 1491-1496, 2014.

[23] IEC 61462, Composite Insulators-Hollow Insulators for Use in Outdoor and Indoor Electrical Equipment-Definitions, Test Methods, Acceptance Criteria and Design Recommendations: IEC 61462, International Electro technical Commission (IEC), Geneva, Switzerland, 2007.

[24] Institute of Electrical and Electronics Engineers, Recommended Practice for Seismic Design of Substations: IEEE Std 693 -2005, IEEE Press, New York, NY, USA, 2006.

[25] R. K. Mohammadi, V. Akrami, and F. Nikfar, "Dynamic properties of substation support structures," Journal of Constructional Steel Research, vol. 78, pp. 173-182, 2012.

[26] F. Paolacci and R. Giannini, "Seismic reliability assessment of a high-voltage disconnect switch using an effective fragility analysis," Journal of Earthquake Engineering, vol. 13, no. 2, pp. 217-235, 2009.

[27] GB50260, Code for Design of Seismic of Electrical Installations, Beijing, Chinain Chinese.

[28] P. K. Venkatesh, L. R. Petzold, R. W. Carr et al., "Variational optimisation by the solution of a series of Hamilton-Jacobi equations]," Physica D, vol. 154, no. 1-2, pp. 15-25, 2001. 
[29] Z. L. Liu, Z. C. Lu, B. Y. Zhang et al., "Optimization Research on seismic safety performance of UHV porcelain Bushing Lighting arrester standardization," Power System Technology, vol. 40 , no. 05 , pp. $1570-1575$, 2016, in Chinese. 